\title{
Distribuição de Pressões em Vertedouros em Degraus
}

\author{
Júlio César Olinger \\ UFPR_PR-olinger@lactec.org.br \\ Giorgio Brighetti \\ EPUSP_SP_brighetti@cth.usp.br
}

Recebido: 19/11/02 - revisão: 09/01/03 - aceito: 07/05/03

\begin{abstract}
RESUMO
O avanço da tecnologia do concreto compactado a rolo (CCR) na construção de barragens tem possibilitado a construção de vertedouros em degraus com maior altura, sujeitos a cargas hidráulicas e a vaz̃ões específicas maiores que as convencionalmente sugeridas para projeto. Conseqüentemente, essa evolução, tem causado preocupação aos projetistas com a possibilidade de cavitação incipiente nos degraus localizados a montante da zona aerada. A cavitação nos degraus do vertedouro está associada à presença de pressões negativas, principalmente, na parte superior do espelho do degrau. A determinação analítica/ empírica dessas pressões nos degraus, para escoamentos denominados de "skimming flow", constitui um problema para o qual a solução não se encontra disponivel na bibliografia atual. A falta de critérios de projeto que considerem o risco de cavitação nos degraus conduziu ao estudo sistemático baseado em investigação experimental para a pesquisa da influência das principais variáveis do escoamento na distribuição de pressões ao longo dos degraus. Este trabalbo visou a partir dos resultados da pesquisa, o estabelecimento de parâmetros adimensionais que permitem relacionar o número de Froude do escoamento com as pressões em qualquer posição dos degraus. A obtenção dessas relações constitui a principal contribuição deste estudo para a verificação da possibilidade de cavitação incipiente nos degraus na região não aerada do escoamento. Para sua avaliação, a partir dessas relações, basta o conbecimento da vazão específica (q), da velocidade média do escoamento (U), da profundidade do escoamento na posição do degrau considerado (b), da declividade da calha (i) e da rugosidade (k), definida como a altura do degrau normal ao plano da calha. Este projeto teve a contribuição da Financiadora de Estudos e Projetos - FINEP (RECOPE/REHIDRO/SUB REDE 2) na compra do sistema de aquisição de dados e dos transdutores de pressão.
\end{abstract}

Palavras-Chave: Vertedouros em degraus; barragens; distribuição de pressão.

\section{INTRODUÇÃO}

Recentes avanços tecnológicos têm permitido a construção de grandes barragens. Na maioria dessas barragens deve-se prever a construção de dispositivos que permitam a passagem da água para jusante. Dentre os dispositivos, destaca-se o vertedouro, que caracteriza-se por uma estrutura que permite a passagem de uma enchente, garantindo a integridade da obra durante a ocorrência das cheias. Se o vertedouro não cumpre esta função, a barragem poderá ser galgada e a sua estabilidade ficará comprometida, podendo eventualmente verificar-se o seu colapso.

Os vertedouros são órgãos importantes para a segurança das barragens, e o seu dimensionamento requer imaginação e experiência do projetista para ponderar a influência de vários fatores ligados à concepção de tais estruturas hidráulicas.

Sabe-se que a toda barragem se associa um desnível e a conseqüente aceleração dos escoamentos na sua transposição, originando fluxos de alta velocidade na base. A dissipação de energia ao longo das transposições é muito pequena, pois, por razões práticas e econômicas, o percurso dos escoamentos é normalmente curto e se faz sobre contornos lisos. Assim, altas concentrações de energia são normais na base dos vertedouros e ações dinâmicas importantes são comuns a essa região, conduzindo a reflexos negativos de várias naturezas.

Nos projetos de vertedouros, em geral, utilizam-se cristas executadas em concreto alisado definidas por formas totalmente consagradas, objetivando manter as pressões compatíveis com um desempenho da estrutura isento de problemas. A calha que se segue à estrutura da crista é normalmente alisada para evitar riscos com cavitação, principalmente quando sujeita a escoamentos de alta velocidade. Conseqüentemente, apenas pequena parcela da energia do escoamento é dissipada ao longo da calha, tornando-se necessária a utilização de estruturas de dissipação de energia, que podem envolver custos elevados de construção. Portanto, o escoamento a jusante de soleiras vertedouras exige uma preocupação especial com a dissipação de sua energia cinética, para que o escoamento na base do vertedouro não ponha em risco a segurança da barragem. 
Uma das formas de dissipar parte da energia cinética é através da construção de degraus ao longo da calha do vertedouro, o que conduz a uma redução da energia específica residual na base do vertedouro. A dissipação de energia causada pelos degraus pode reduzir significativamente o tamanho e o custo da bacia de dissipação necessária na base do vertedouro, comparada com uma calha convencional (calha lisa).

Apesar do conceito do vertedouro em degraus não ser recente, o crescimento do interesse em sua construção foi favorecido pelo uso da tecnologia do concreto compactado a rolo (CCR) na construção das barragens. O processo executivo em camadas de concreto compactado permite, com mais facilidade, a execução do acabamento dos degraus em concreto convencional, além de possibilitar que a declividade definida pelo alinhamento das extremidades dos degraus resulte na própria declividade da calha.

Atualmente, há um interesse crescente no comportamento hidráulico dos vertedouros em degraus nos laboratórios em todo o mundo. O desempenho hidráulico de vários vertedouros em degraus tem sido estudado em modelos reduzidos. As investigações de interesse mais comum têm se concentrado nas características do fluxo, na energia residual no pé do vertedouro e na concentração de ar no escoamento. Entretanto há, ainda, vários aspectos necessitando de investigações adicionais.

Com o avanço tecnológico do CCR, permitindo a construção de barragens mais altas, a adoção nos projetos de vertedouros em degraus de vazões específicas e de velocidades do fluxo mais elevadas, tem aumentado o risco de cavitação, principalmente na zona não aerada do escoamento. A preocupação com o fenômeno da cavitação nos degraus procede em função da possibilidade de danos que possam comprometer a dissipação de energia ao longo dos degraus e por em risco a região à base do vertedouro, além de exigir manutenção periódica nos degraus da calha.

A análise detalhada da bibliografia existente sobre estudos relacionados as pressões em degraus identificou trabalhos de pesquisadores como Tate (1987), Houston (1987), Rubinshteim e Stefanovich (1988), Sanches (1988), Frizzel (1991), Tozzi (1992), Lejeune e Lejeune (1994), Elviro e Mateos (1995), Mejia Fernández (1996) e Matos et al. (1999). Como se pode observar, pesquisas sobre distribuição de pressões nos degraus são muito escassas, mesmo sabendo-se que pressões negativas relativamente altas podem provocar a cavitação incipiente nos degraus submersos no escoamento (skimming flow) não aerado.

Atualmente, não se dispõe de um critério que permita estabelecer, com relativa segurança, as pressões atuantes em um determinado degrau da calha vertedoura sujeito a escoamentos em que os degraus permanecem totalmente submersos (skimming flow).

A identificação das condições incipientes de cavitação no fluxo não aerado permitirá avaliar a possibilidade de se adotar o vertedouro em degraus para cargas mais altas, superiores aos $3-4 \mathrm{~m}\left(10-15 \mathrm{~m}^{3} / \mathrm{s} . \mathrm{m}\right)$ atualmente aceitos como limites práticos.

Neste trabalho, estudou-se a distribuição de pressões que ocorre nos degraus do vertedouro. Especificamente, investigou-se as condições médias do escoamento e a questão da cavitação incipiente nos vertedouros em degraus, no trecho a montante da zona aerada.

\section{INSTALAÇÃO EXPERIMENTAL ENSAIOS REALIZADOS}

\section{Configuração do modelo}

Para a execução do estudo proposto construíu-se um modelo bidimensional de uma calha vertedoura em degraus com inclinação do paramento de $1 \mathrm{~V}: 0,75 \mathrm{H}$. A instalação experimental, construída no Centro de Hidráulica e Hidrologia Prof. Parigot de Souza - CEHPAR, apresentada nas figuras 1 e 2, foi implantada engastada e devidamente apoiada sob uma caixa de água elevada através de uma tubulação metálica de $300 \mathrm{~mm}$ composta de um medidor de vazão do tipo Venturi e de um registro de gaveta para o controle da vazão. $\mathrm{Na}$ seqüência, após um trecho de tubulação em transição, a calha do vertedouro com seção transversal de 0,125 m x 0,300 m, 7,5 m de comprimento e $6 \mathrm{~m}$ de altura, possui uma seção estrangulada móvel (figura 3) para definição das condições do escoamento efluente sobre um trecho com fundo liso seguido de 36 degraus com 0,12 m x 0,09 m. Para melhorar as condições de escoamento, após o trecho com fundo liso, construíu-se um conjunto de degraus menores, com tamanhos crescentes, correspondentes às relações 1:4 e 1:2 dos degraus normais, sobrepostos aos primeiros degraus da calha (figura 3).

A estrutura da calha foi confeccionada em acrílico transparente, de textura lisa, para permitir uma boa visualização das condições gerais de escoamento.

A vazão imposta para cada teste é controlada pela seção estrangulada, a qual define, a princípio, a profundidade do escoamento (D) até além do degrau dotado de piezômetros. O escoamento aerado em função da macro rugosidade (k) no fundo da calha (degraus), conduz à turbulência do escoamento que se desenvolve gerando a camada limite turbulenta que atinge a superfície do jato em um ponto a jusante do degrau instrumentado.

\section{Comportamento genérico do escoamento}

A vazão afluente à instalação deriva da caixa de água elevada na cota $11,80 \mathrm{~m}$ e escoa através de uma tubulação metálica de $300 \mathrm{~mm}$ dotada de um medidor de vazão do tipo Venturi. As vazões são obtidas a partir da leitura da diferença de pressão no manômetro diferencial instalado anexo à plataforma. A plataforma permite acesso ao regis- 
tro que controla a vazão (figura 2). $\mathrm{O}$ medidor Venturi foi calibrado no CEHPAR e permite, para as condições de sua instalação, a passagem de vazões da ordem de $250 \mathrm{l} / \mathrm{s}$. Após o registro de gaveta, o escoamento passa por um tubo que serve como transição, ligando a seção do tubo circular de metal na saída do registro até um tubo de seção retangular no início da calha de acrílico.

Este tubo retangular de acrílico faz a aproximação do escoamento à seção de estrangulamento móvel, também denominado de ejetor, que permite a imposição de aberturas de até $0,20 \mathrm{~m}$. A superfície livre da água no trecho imediatamente a jusante da saída do ejetor é praticamente paralela ao plano de inclinação da calha. A superfície da água apresenta uma aparência alisada e revela a presença de aeração superficial junto às paredes laterais de acrílico da calha. No interior do escoamento, incluindo os degraus, não observa-se a presença de ar. $\mathrm{O}$ ar arrastado concentrase mais junto às laterais devido ao efeito de parede.

O escoamento na instalação experimental (figura 2) identifica um grande trecho da calha com escoamento não aerado. A observação do escoamento, diretamente no modelo, permite identificar na superfície livre da água a posição do início da aeração, que parece coincidir com o local onde a camada limite atinge a superfície livre da água. A região do escoamento totalmente aerado define-se no trecho médio de jusante da calha. No final da calha o escoamento mergulha em uma cisterna a céu aberto ( elevação $1,50 \mathrm{~m}$ ) que serve para a dissipação da energia residual. A água desta cisterna é recalcada para uma outra cisterna subterrânea que armazena a água necessária ao funcionamento do laboratório. Através de bombeamento a água deste reservatório alimenta a caixa de água elevada.

\section{Análise dimensional}

Considera-se que os principais parâmetros intervenientes no processo de cavitação incipiente são:

$$
\begin{aligned}
& p=\text { pressão }\left(\mathrm{N} / \mathrm{m}^{2}\right) ; \\
& \rho=\text { massa específica do fluido }\left(\mathrm{kg} / \mathrm{m}^{3}\right) ; \\
& g=\text { aceleração da gravidade }\left(\mathrm{m} / \mathrm{s}^{2}\right) ; \\
& U=\text { velocidade média do escoamento }(\mathrm{m} / \mathrm{s}) ; \\
& h=\text { profundidade do escoamento }(\mathrm{m}) ; \\
& k=\text { rugosidade }- \text { altura dos degraus }(\mathrm{m}) ; \\
& i=\text { declividade da calha }(\mathrm{m} / \mathrm{m}) .
\end{aligned}
$$

A análise dimensional dessas variáveis conduz à seguinte expressão:

$$
p=\gamma \frac{U^{2}}{2 g} . \mathrm{f}(F, h / k, i),
$$

com $F$ simbolizando o número de Froude do escoamento $\left(F=\frac{U}{\sqrt{g h}}\right)$ e $\gamma$ o peso específico do fluido $(\gamma=\rho g)$.

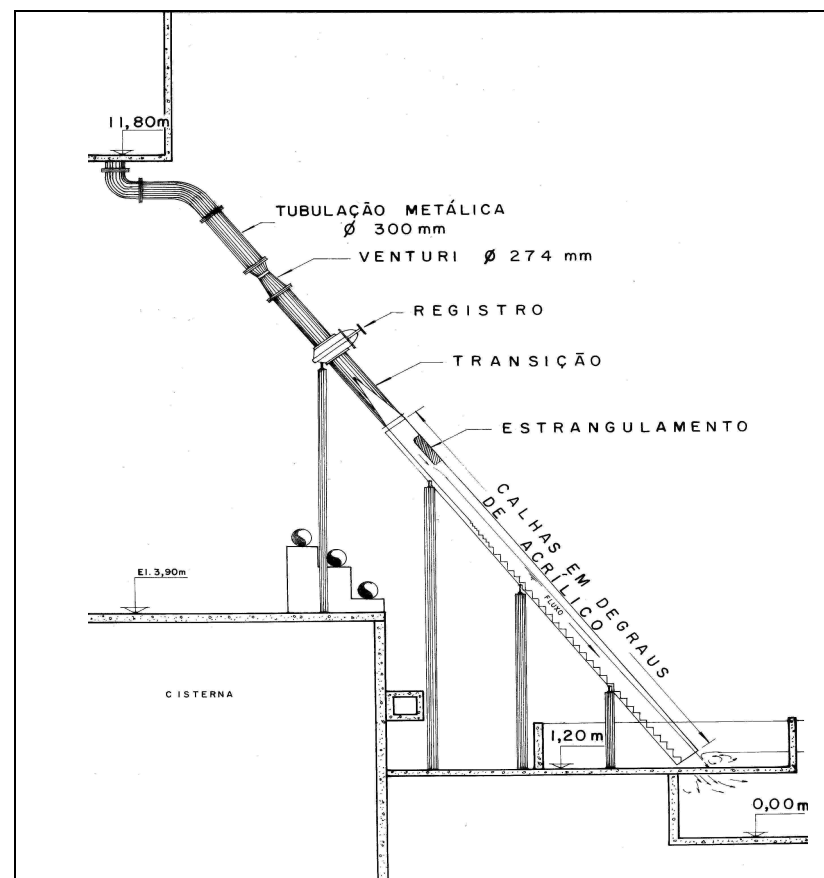

Figura 1 - Características gerais do modelo experimental

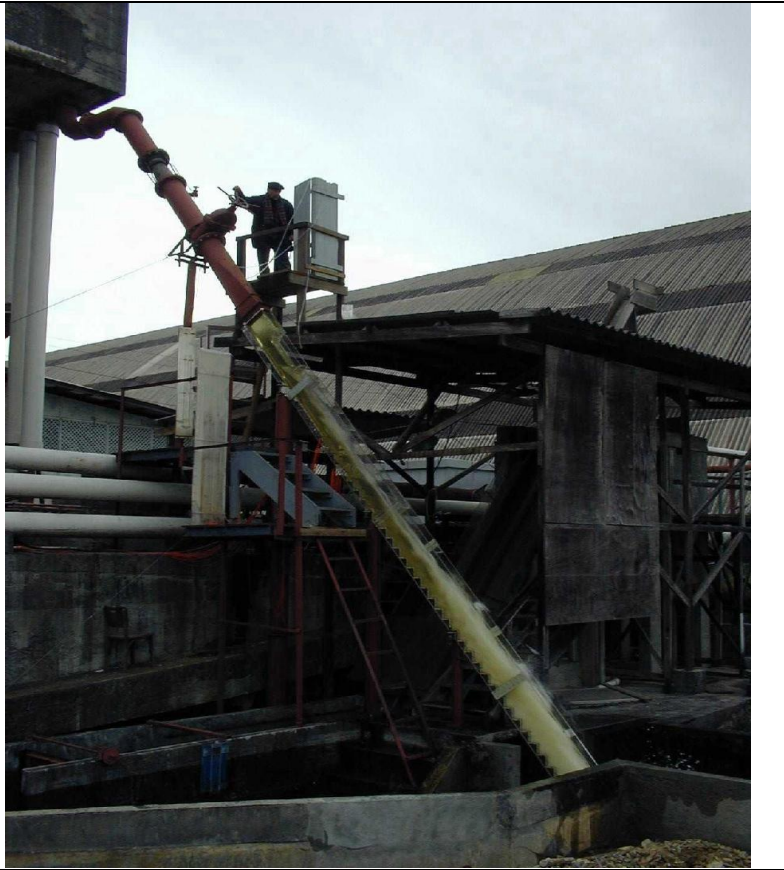

Figura 2. Vista geral do modelo em operação. 
Como no presente estudo a declividade da calha foi mantida constante, tem-se:

$$
\frac{p}{\gamma \frac{U^{2}}{2 g}}=\mathrm{f}(F, h / k)
$$

\section{Ensaios realizados}

As investigações na instalação experimental compreenderam a realização de 3 séries de ensaios, correspondendo cada série de ensaio a um tamanho de degrau:

- $\quad$ Série 01 - degraus com 0,12 m x 0,09 m - ver figura 4;

- Série 02 - degraus com $0,06 \mathrm{~m}$ x $0,045 \mathrm{~m}$ - ver figura 5 ;

- Série 03 - degraus com $0,03 \mathrm{~m}$ x 0,0225 m - ver figura 6.

Cada série é composta de um conjunto de ensaios, que por sua vez são constituídos de vários testes. Cada série relacionou-se a uma escala geométrica vinculada com o degrau padrão normalmente usado nos protótipos (altura de 0,60 m). Cada ensaio correspondeu a uma condição de abertura do ejetor que define uma profundidade de escoamento sobre os degraus.

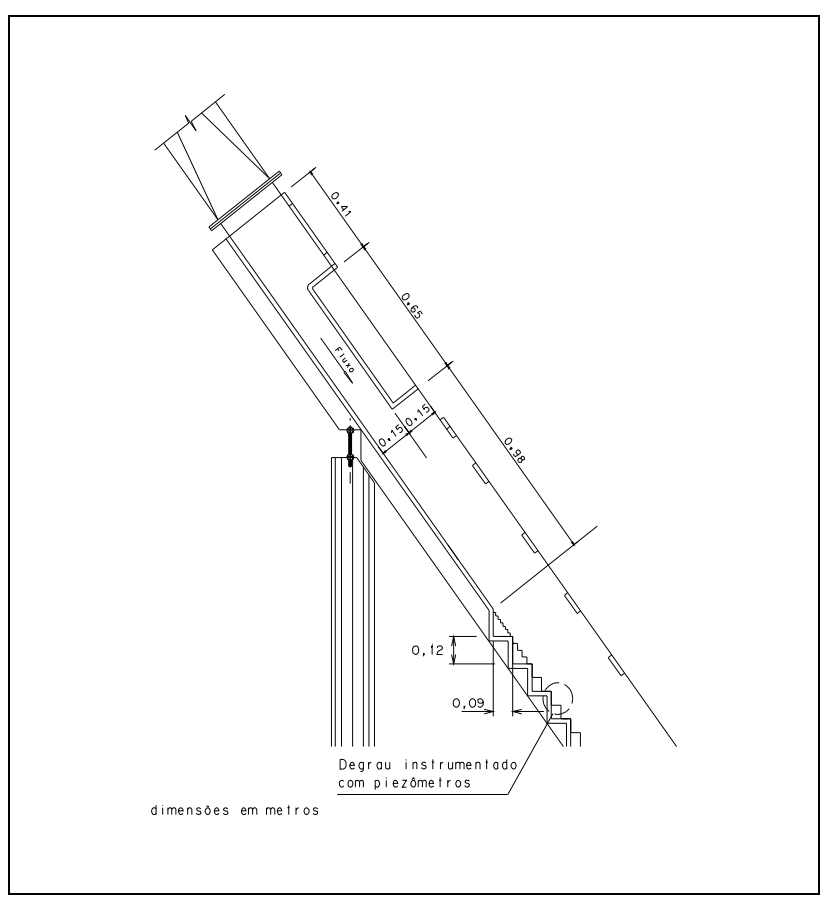

Figura 3 - Vista parcial da calha mostrando o trecho liso e a transição de degraus.

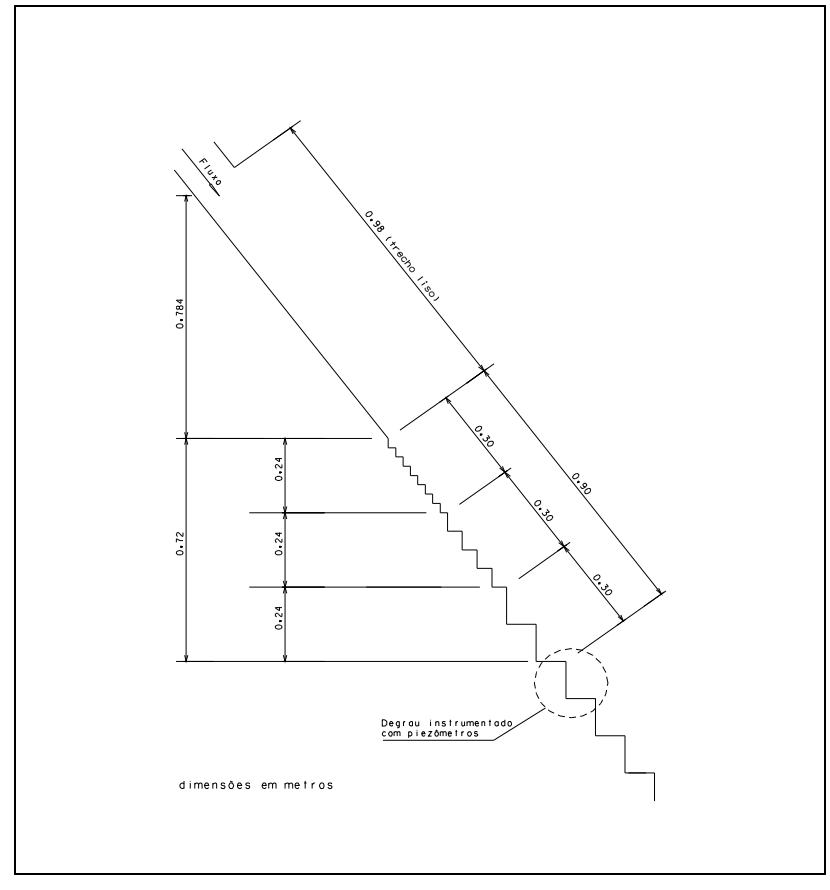

Figura 4 - Configuração da calha ilustrando os degraus com 0,12 $\mathrm{m}$ x 0,09 m - série 01. (Escala geométrica 1:5).

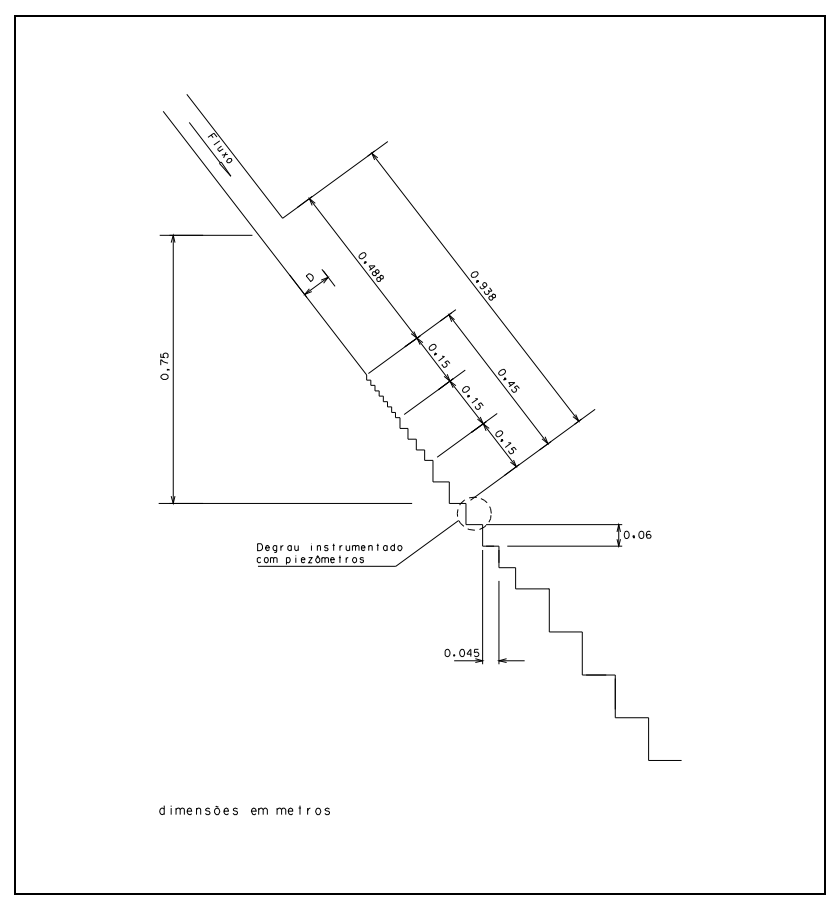

Figura 5 - Configuração da calha ilustrando os degraus com 0,06 m x 0,045 m - série 02. (Escala geométrica 1:10).

\section{Pressões nos degraus}

Em todos os testes realizados foram determinadas as pressões máximas e mínimas ao longo de um degrau 
instrumentado com piezômetros convencionais. Os degraus onde foram determinadas as pressões, nos testes das séries 01 e 02 , foram instrumentados com 16 piezômetros instalados no eixo da calha (figura 7). O degrau na série 03, foi instrumentado com 14 piezômetros, foram excluídos os piezômetros extremos 1 e 16, localizados no espelho e na face horizontal do degrau respectivamente.

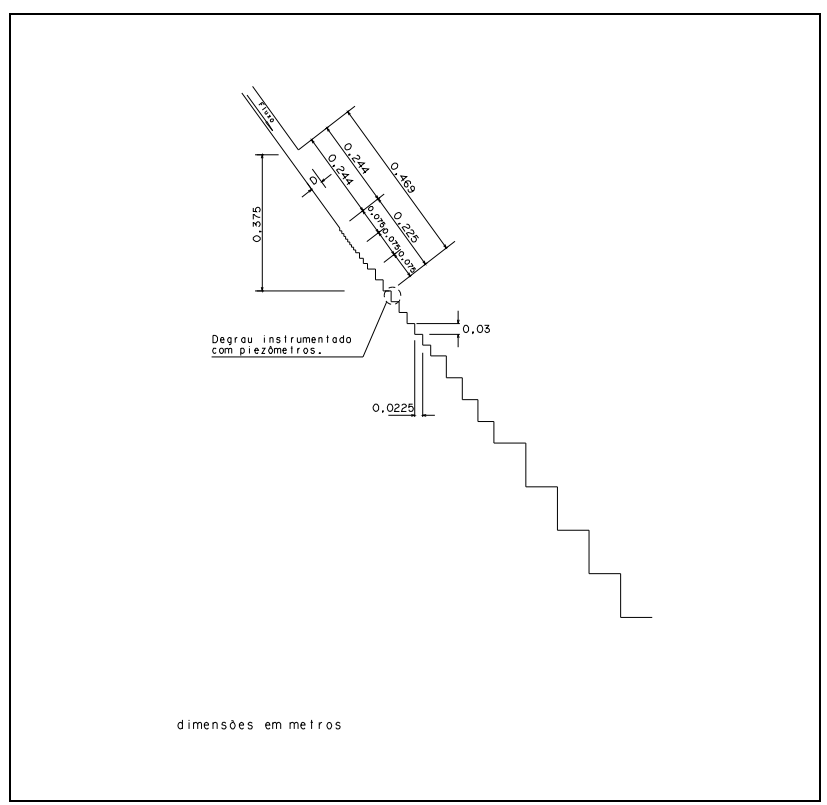

Figura 6 - Configuração da calha ilustrando os degraus com $0,03 \mathrm{~m} \times 0,0225 \mathrm{~m}$-série 03. (Escala geométrica 1:20).

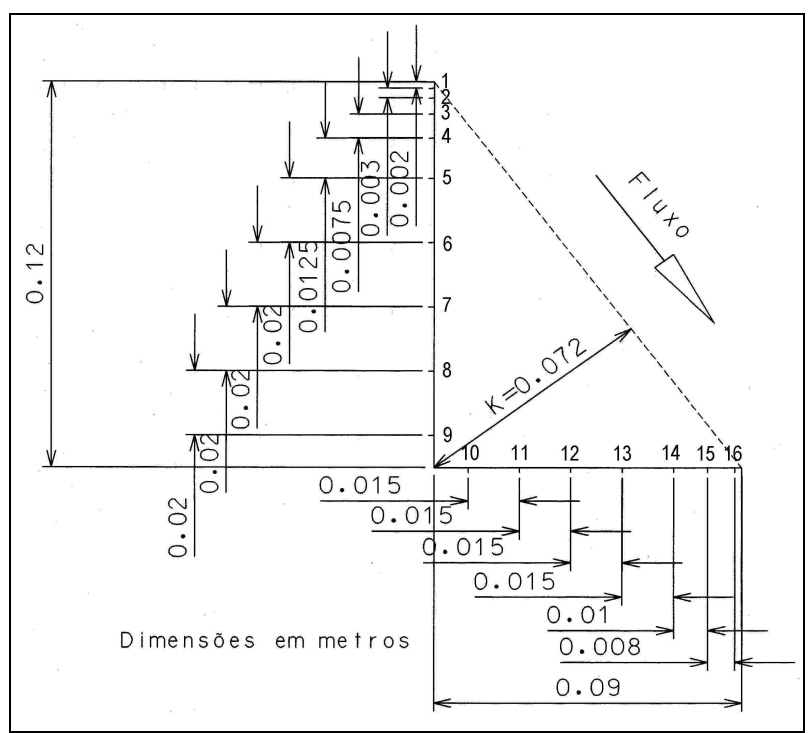

Figura 7 - Configuração geral dos piezômetros implantados no degrau.

\section{Distribuição de velocidades}

As distribuições de velocidades do fluxo foram determinadas nos testes realizados com semelhança geométrica e cinemática do escoamento. Nestes testes foram determinados perfis de velocidade na seção perpendicular ao plano da calha, localizada no alinhamento da quina superior do degrau instrumentado com piezômetros. Em cada teste, determinou-se 3 perfis de velocidade, um no eixo da calha e os outros dois afastados das paredes laterais de $0,032 \mathrm{~m}$. A título investigativo, em alguns destes testes, levantou-se, também, o perfil de velocidade na posição final do trecho liso, para avaliação do desenvolvimento da camada limite. As velocidades foram medidas com um tubo de estagnação, ilustrado na figura 8.

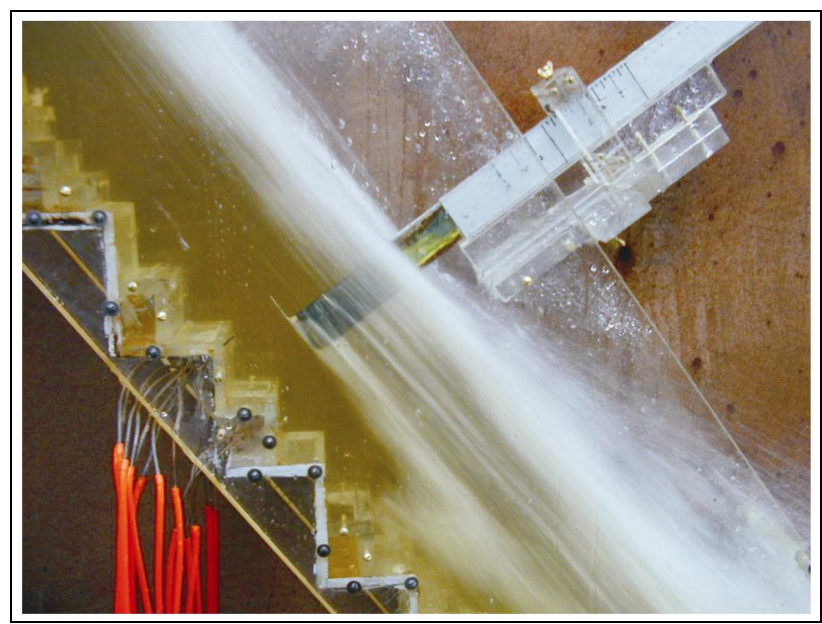

Figura 8 - Tubo de estagnação sobre o degrau instrumentado com piezômetros.

\section{Pressões instantâneas}

Os resultados dos testes até aqui realizados, obtidos nas três configurações de degraus, séries de ensaios 01 a 03, revelaram a partir do levantamento das pressões médias, através de piezômetros convencionais, a existência de pressões negativas na região correspondente ao espelho do degrau. Com o objetivo de investigar o risco incipiente de cavitação na região não aerada do escoamento, foram implantados nos degraus, instrumentados com piezômetros, transdutores de pressão (figura 9) conectados a um microcomputador (figuras 10 e 11). As leituras das pressões instantâneas foram efetuadas através de transdutores de pressão da marca Hytronic ( faixa entre: -500 mbar a +500 mbar). Essas medidas de pressão instantânea são adequadas à determinação da flutuação das pressões e de suas freqüências. A determinação das pressões instantâneas nos degraus foi efetuada para o conjunto de testes indicados no quadro 1. 
Quadro 1 - Testes realizados com medição de pressão instantânea.

\begin{tabular}{|c|c|c|c|c|c|c|c|}
\hline ESCALA & SÉRIE & ENSAIO & TESTE & $\begin{array}{c}\text { VAZÃO } \\
\text { (mod.) } \\
\text { Q } \\
\left(\mathrm{m}^{3} / \mathrm{s}\right)\end{array}$ & $\begin{array}{c}\text { VELOC. } \\
\text { (mod.) } \\
\mathrm{v} \\
(\mathrm{m} / \mathrm{s})\end{array}$ & $\begin{array}{c}\text { VAZÂ0 } \\
\text { (prot.) } \\
q \\
\left(\mathrm{~m}^{3} / \mathrm{s} . \mathrm{m}\right)\end{array}$ & $\begin{array}{c}\text { VELOC. } \\
\text { (prot.) } \\
\mathrm{v} \\
(\mathrm{m} / \mathrm{s})\end{array}$ \\
\hline \multirow{6}{*}{$1: 5$} & \multirow{6}{*}{01} & \multirow{3}{*}{01} & 01 & 0.246 & 9.836 & 21.994 & 21.99 \\
\hline & & & 02 & 0,201 & 8,021 & 17,936 & 17,94 \\
\hline & & & 03 & 0,150 & 5,994 & 13,403 & 13,40 \\
\hline & & \multirow{3}{*}{02} & 01 & 0.201 & 10.695 & 17.936 & 23.92 \\
\hline & & & 02 & 0,150 & 7,992 & 13,403 & 17,87 \\
\hline & & & 03 & 0,112 & 5,992 & 10,049 & 13,40 \\
\hline \multirow{9}{*}{$1: 10$} & \multirow{9}{*}{02} & \multirow{4}{*}{03} & 04 & 0.100 & 7.992 & 25.273 & 25.27 \\
\hline & & & 05 & 0,089 & 7,122 & 22,522 & 22,52 \\
\hline & & & 06 & 0,071 & 5,651 & 17,871 & 17,87 \\
\hline & & & 07 & 0,054 & 4,334 & 13,706 & 13,71 \\
\hline & & \multirow{5}{*}{04} & 04 & 0.100 & 10.656 & 25.273 & 33.70 \\
\hline & & & 05 & 0,086 & 9,137 & 21,671 & 28,90 \\
\hline & & & 06 & 0,071 & 7,535 & 17,871 & 23,83 \\
\hline & & & 07 & 0,053 & 5,633 & 13,359 & 17,81 \\
\hline & & & 08 & 0,040 & 4,286 & 10,165 & 13,55 \\
\hline \multirow{12}{*}{$1: 20$} & \multirow{12}{*}{03} & \multirow{6}{*}{01} & 01 & 0.068 & 10.879 & 48.652 & 48.65 \\
\hline & & & 02 & 0,055 & 8,776 & 39,249 & 39,25 \\
\hline & & & 03 & 0,042 & 6,715 & 30,029 & 30,03 \\
\hline & & & 04 & 0,031 & 4,942 & 22,101 & 22,10 \\
\hline & & & 05 & 0,026 & 4,112 & 18,389 & 18,39 \\
\hline & & & 06 & 0,019 & 3,065 & 13,706 & 13,71 \\
\hline & & \multirow{6}{*}{02} & 01 & 0.049 & 10.498 & 35.212 & 46.95 \\
\hline & & & 02 & 0,043 & 9,137 & 30,648 & 40,86 \\
\hline & & & 03 & 0,032 & 6,838 & 22,935 & 30,58 \\
\hline & & & 04 & 0,026 & 5,482 & 18,389 & 24,52 \\
\hline & & & 05 & 0,019 & 4,086 & 13,706 & 18,27 \\
\hline & & & 06 & 0,014 & 2,947 & 9,884 & 13,18 \\
\hline
\end{tabular}

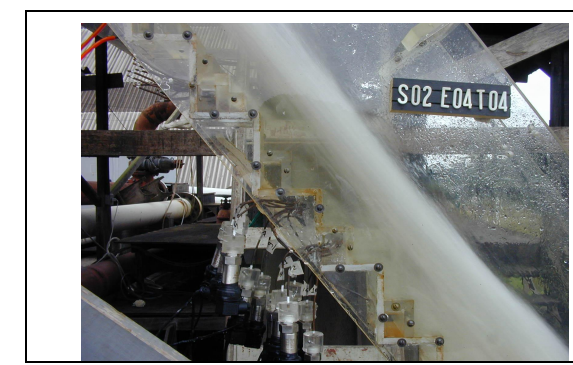

Figura 9 - Transdutores de pressão instalados no degrau.

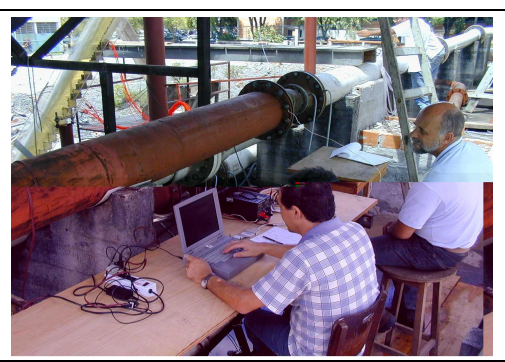

Figura 10 - Medição das pressões instantâneas.

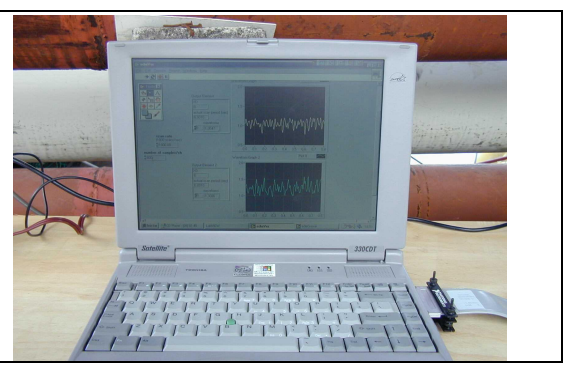

Figura 11 - Tela com gráficos de flutuações de pressões. 
Resultados e análise

Em todos os testes realizados determinaram-se através dos piezômetros convencionais e dos transdutores de pressão as distribuições de pressão máxima, mínima e média, bem como, as distribuições de velocidades, medidas a partir de um tubo de estagnação - ilustrado na figura 8 .

Os resultados de pressão média obtidos através dos piezômetros convencionais e a partir dos transdutores de pressão foram confrontados.
Desse confronto verificou-se que os resultados de pressão média foram consistentes e semelhantes, fato que sintetiza a boa calibragem dos transdutores de pressão, por ocasião das medições de pressões instantâneas. A figura 12 ilustra as flutuações de pressão instantâneas observadas nos transdutores instalados nos piezômetros 1, 2, 3 e 5 , no teste 01 - série 01 ; ensaio 01 . Os resultados de pressão média para esse mesmo teste, medidos nos piezômetros e nos transdutores, estão representados na figura 13.
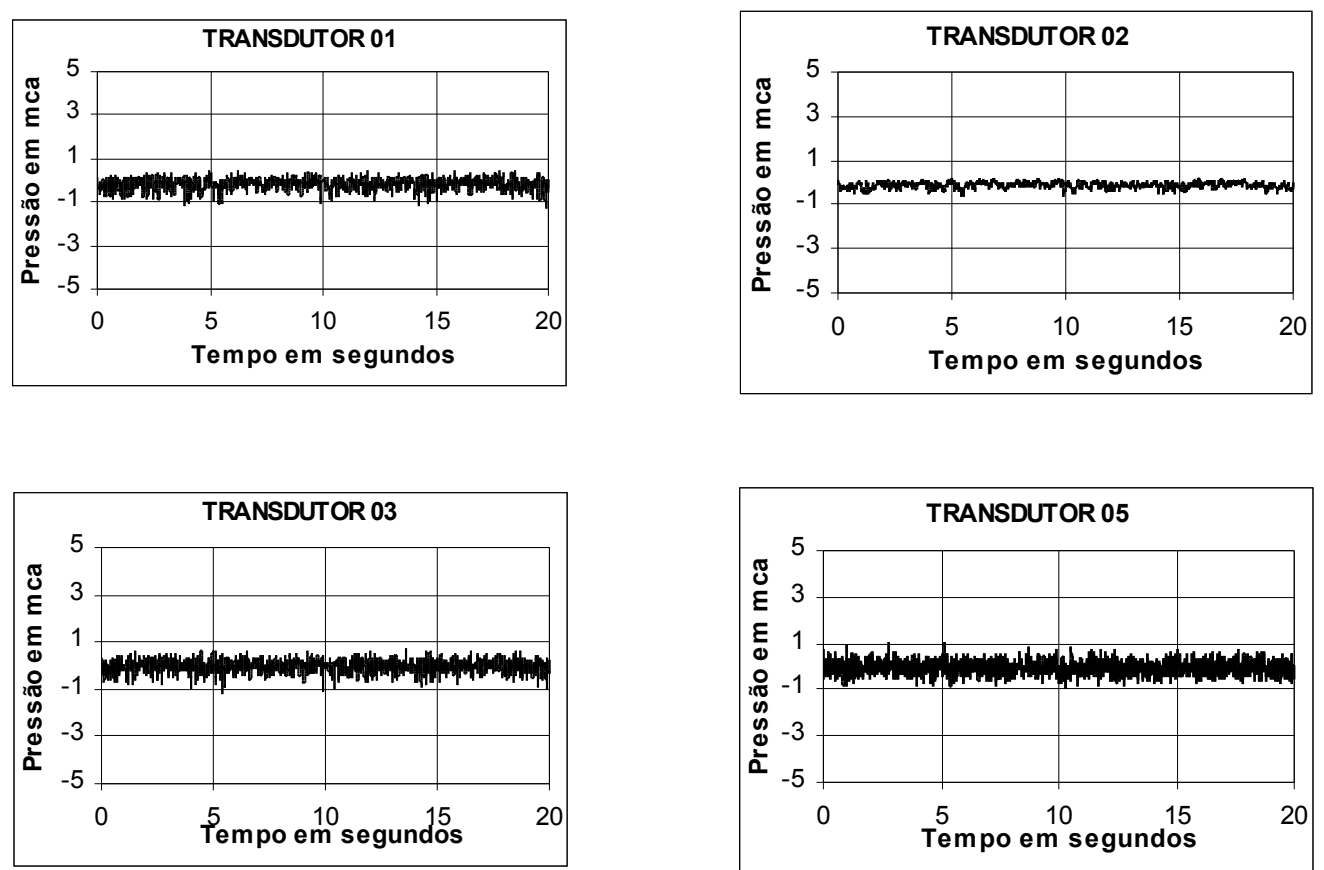

Figura 12 - Flutuações de pressão instantânea - série 01; ensaio 01; teste 01.

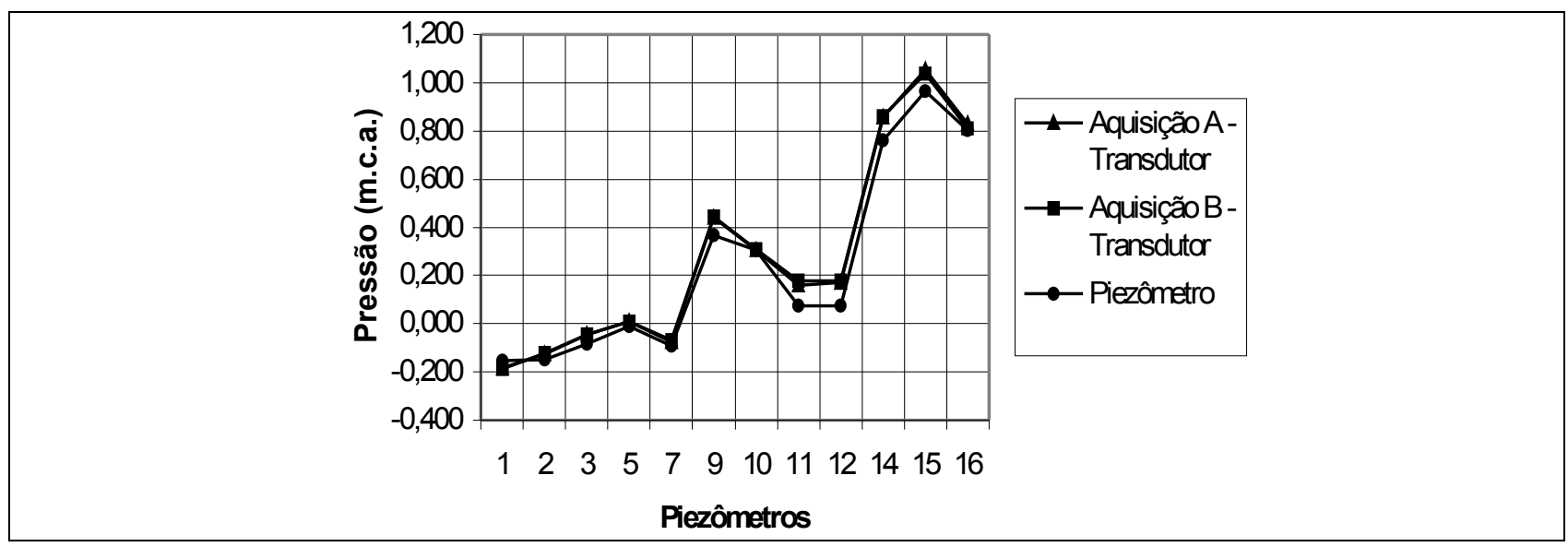

Figura 13 - Confronto entre pressões médias - série 01; ensaio 01; teste 01. 


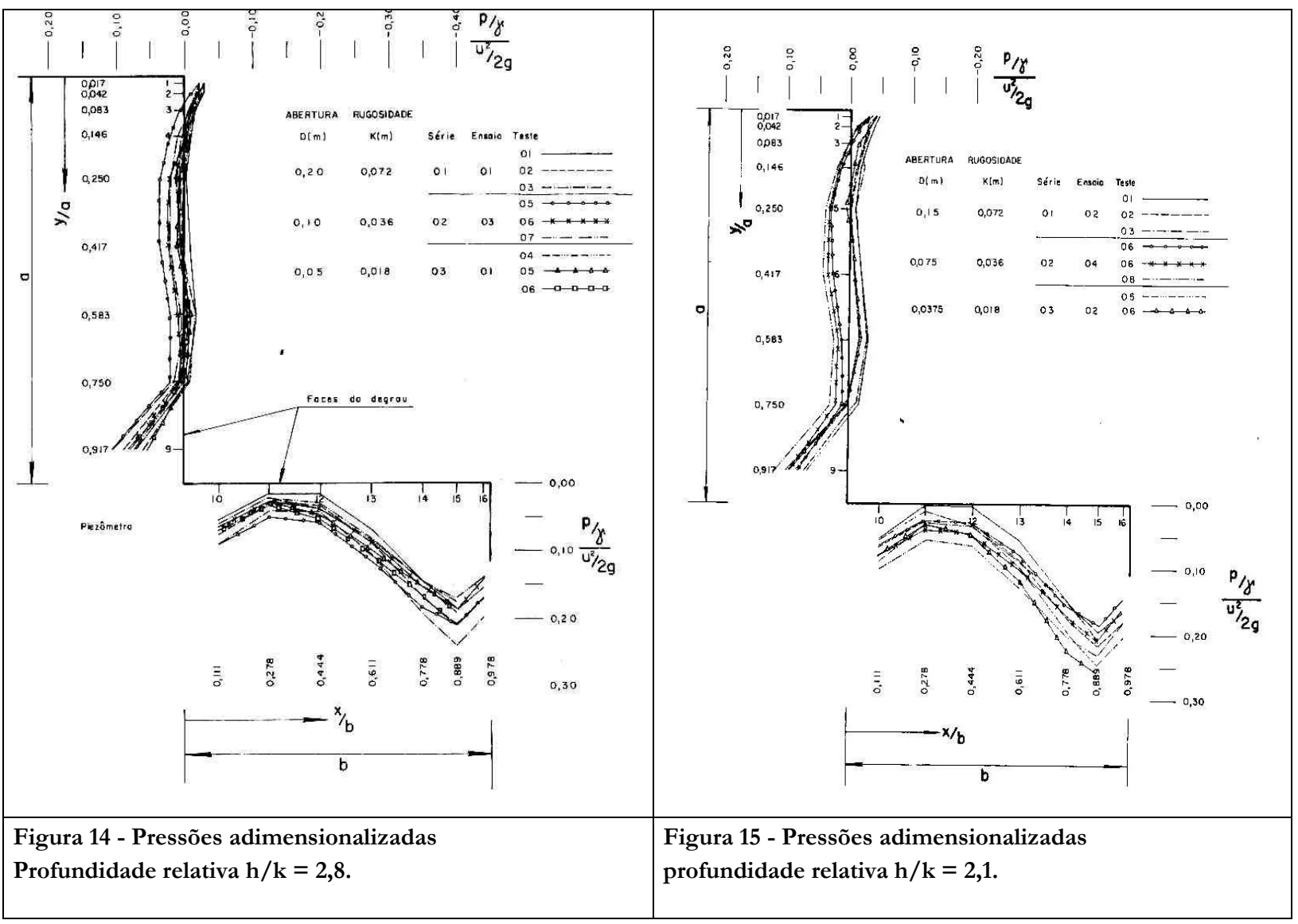

As distribuições de pressão sobre o degrau, obtidas nos testes realizados com semelhança geométrica e semelhança cinemática do escoamento, simulados para as duas condições de profundidade do escoamento (D) iguais a $0,15 \mathrm{~m}$ e $0,20 \mathrm{~m}$, identificadas no quadro I, conduziram a uma análise adimensional dos resultados. As pressões médias $(p / \gamma)$, obtidas com os piezômetros convencionais foram adimensionalizadas com relação à energia cinética do escoamento $\left(U^{2} / 2 g\right)$. Essas distribuições de pressão adimensionalizadas estão representadas nas figuras 14 e 15.

As distribuições de velocidades adimensionalizadas (profundidade relativa $\mathrm{y} / \mathrm{h}$ versus velocidade relativa $\mathrm{v} / \mathrm{v}_{\text {máx. }}$ ), obtidas para as duas condições de profundidade do escoamento, simuladas em três degraus com escalas diferentes, foram confrontadas para verificação da homogeneidade dos dados medidos. Os confrontos dos perfis de velocidades estão apresentados nas figuras 16 e 17 . As figuras mostram distribuições de velocidades bem definidas e coerentes com o tipo de escoamento simulado. Essas figuras, adicionalmente, ilustram a representação da distribuição de velocidades logarítmica proposta por Tozzi
(1992), plotada no trecho do perfil de velocidades definido pelo desenvolvimento da camada limite turbulenta do escoamento. A curva proposta ajustou-se bem aos resultados experimentais do presente estudo.

A variação das pressões adimensionalizadas $\left(p / \gamma / U^{2} / 2 g\right)$ com o número de Froude do escoamento F para as relações $\mathrm{h} / \mathrm{k}$ testadas são ilustradas graficamente nas figuras 18 e 19 . As pressões médias no piezômetro 1, no espelho do degrau, adimensionalizadas, são plotadas contra o número de Froude do escoamento na figura 18. As pressões médias negativas são essencialmente independentes do número de Froude. A figura 19 ilustra as pressões adimensionalizadas medidas no piezômetro 15 , no piso do degrau, local onde ocorrem as maiores pressões positivas, provocadas pelo impacto do jato de água sobre o degrau. Apresenta-se nessa figura a relação resultante expressa por duas curvas ajustadas aos resultados adimensionalizados. Essas curvas representam em termos médios as relações $\mathrm{h} / \mathrm{k}$ iguais a 2,1 e 2,8 . 

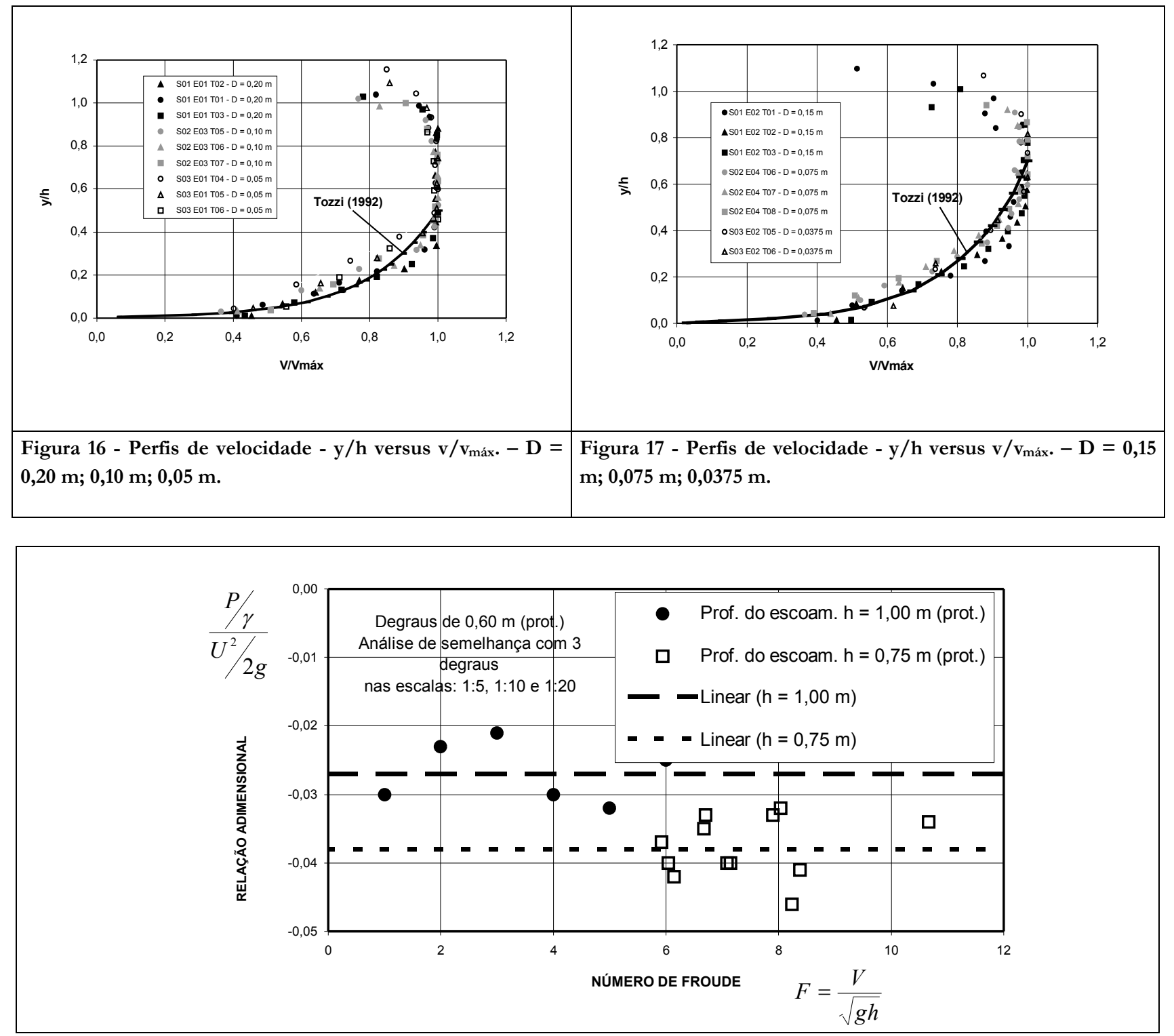

Figura 18 - Pressões médias adimensionalizadas versus número de Froude - piezômetro 1.

As aquisições das flutuações de pressões instantâneas permitiram estabelecer as probabilidades de ocorrência das pressões sub-atmosféricas que atingem o valor da pressão de vapor $\left(\mathrm{p}_{\mathrm{v}}\right)$, na prática, da ordem de $-9,5$ m.c.a. a $\quad-10$ m.c.a. Os testes e os piezômetros em que ocorreram essas pressões, bem como a freqüência de ocorrência foram identificados.

Visando avaliar a consistência das aquisições das pressões instantâneas, bem como o comportamento de sua freqüência, construíu-se, para os testes realizados, as curvas de permanência das freqüências das pressões adquiridas nas posições dos piezômetros 1, 2, 3 e 5 . A figura 20 apresenta as curva de freqüência das pressões instantâneas obtidas nos testes da série 02 - ensaio 04 , no piezômetro 1. A análise dessas curvas de freqüência, bem como das outras analisadas para os outros piezômetros, identifica uma mesma tendência na distribuição das freqüências e uma boa consistência dos resultados.

Também foram efetuadas, para os testes, avaliações das pressões instantâneas relacionadas à sua freqüência e à velocidade média do escoamento. A plotagem dessas variáveis para os testes da série 02 - ensaio 04, no piezômetro 1, encontram-se configuradas, respectivamente, nas figuras 21 e 22 . Nessas figuras, observa-se que quanto maior a velocidade média do escoamento mais negativas são as pressões com freqüência menor. 


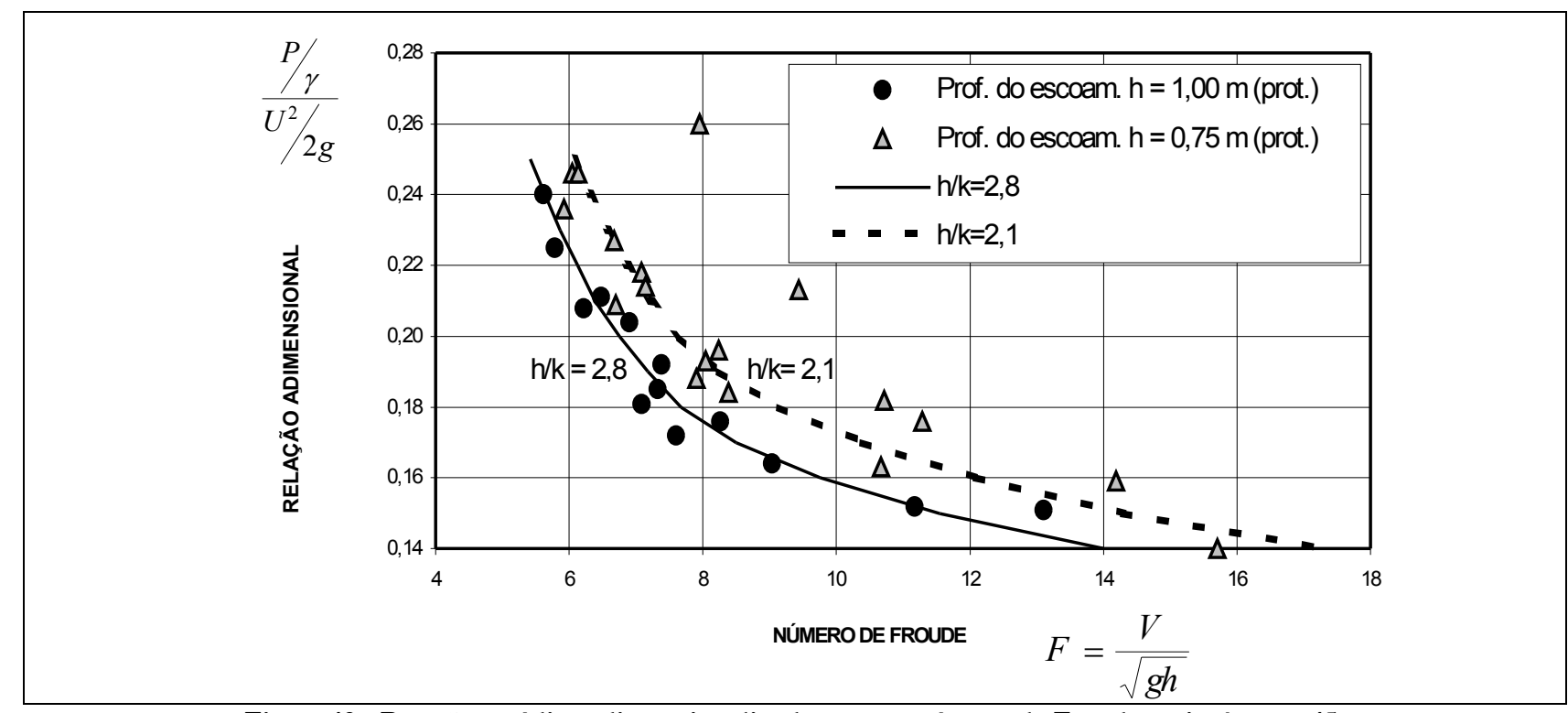

Figura 19 - Pressões médias adimensionalizadas versus número de Froude - piezômetro 15.

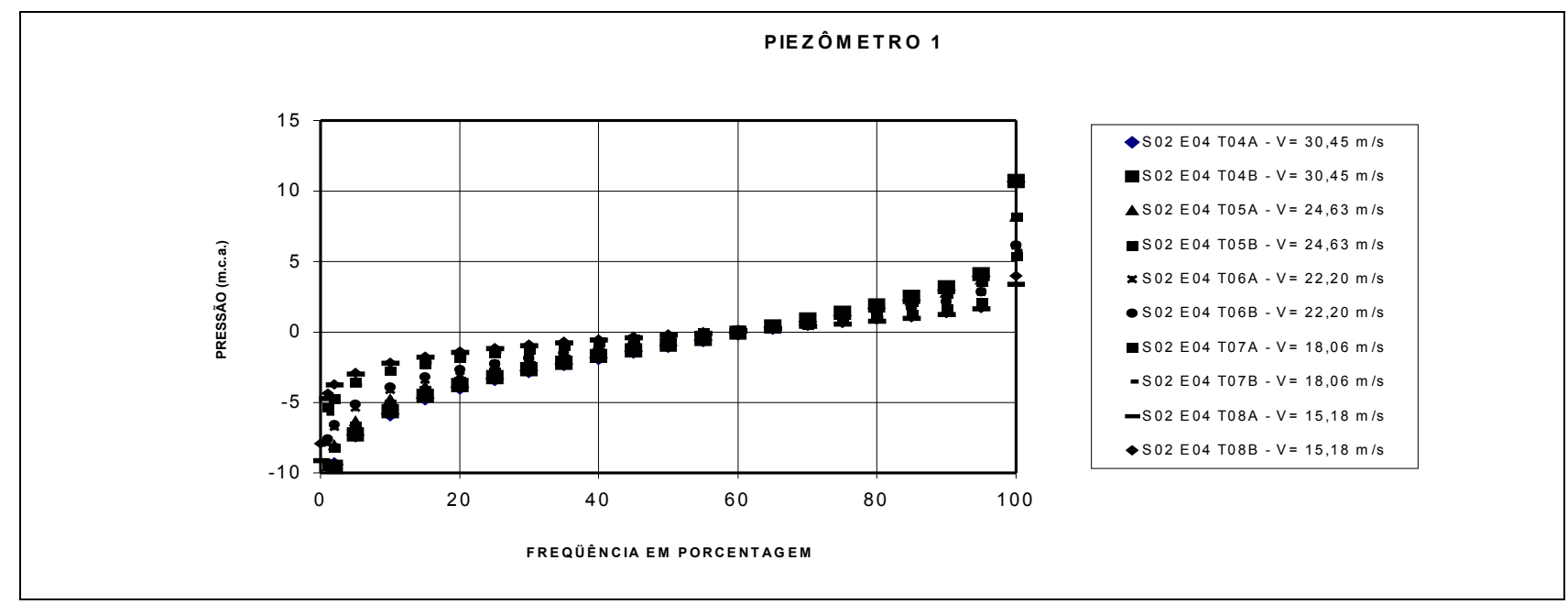

Figura 20 - Distribuição de freqüências das pressões em porcentagem - série 02 ; ensaio 04.

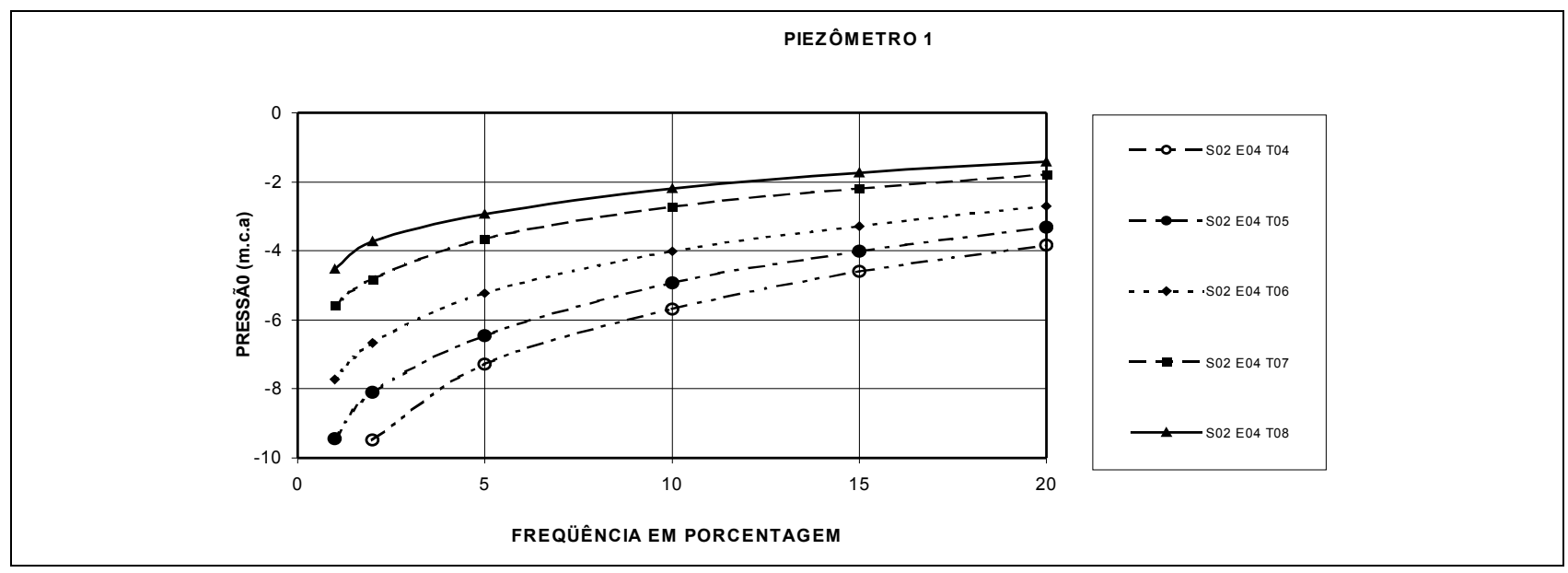

Figura 21 - Distribuição de freqüências das pressões em porcentagem - série 02 ; ensaio 04. 


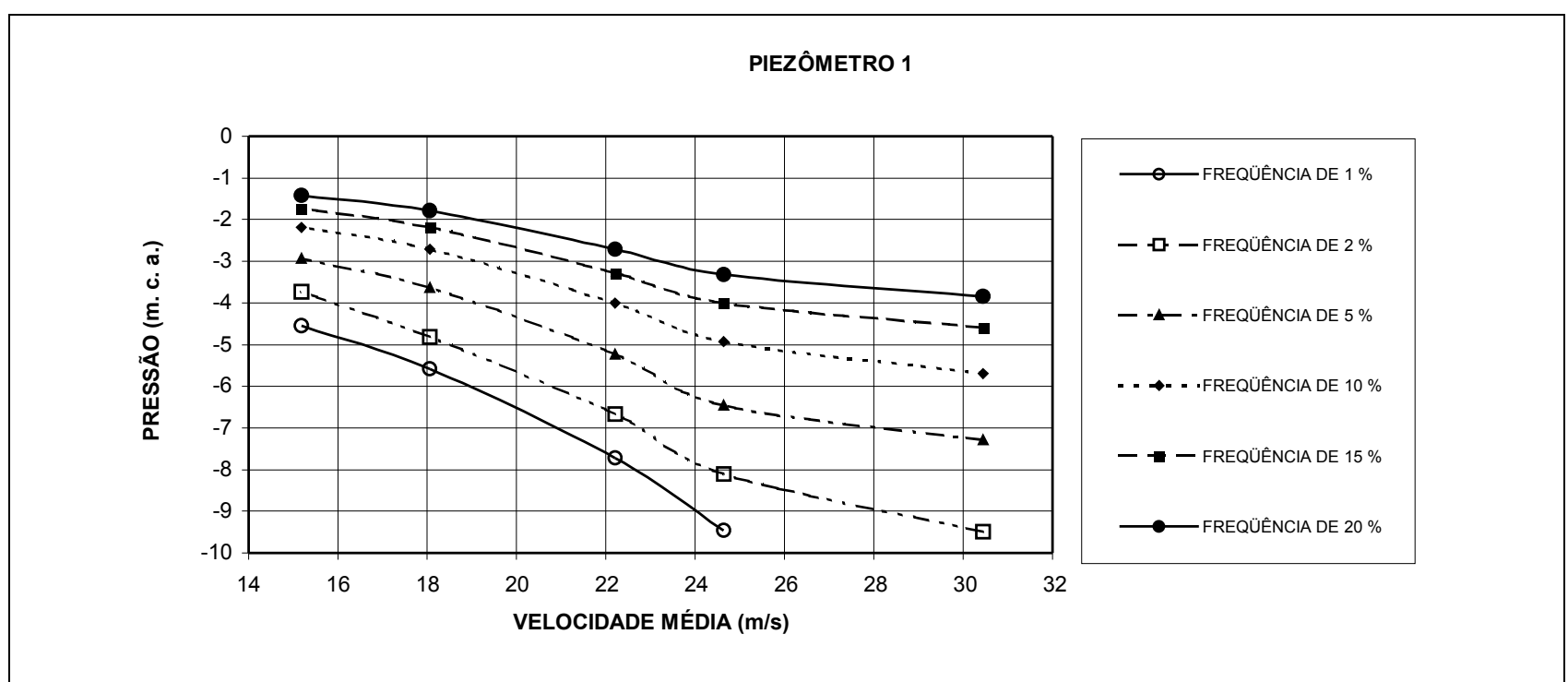

Figura 22 - Distribuição das pressões instantâneas relacionada as freqüências de ocorrência e as velocidades médias do escoamento - testes da série 02 ; ensaio 04.

Após essa análise detalhada das pressões instantâneas obtidas nos testes, buscou-se avaliar o risco de incipiência de cavitação nos degraus, baseando-se na freqüência das pressões instantâneas que atingiram níveis de pressão sub-atmosférica. Nos testes, as pressões negativas mais significativas ocorreram nos piezômetros 1, 2, 3 e 5, localizados no espelho do degrau (figura 7).

$\mathrm{Na}$ avaliação do risco de cavitação nos degraus considerou-se a conclusão obtida por Lopardo et al. (1982) em suas investigações sobre cavitação induzida em bacias de dissipação por flutuações de pressão. Os autores concluíram que a cavitação na bacia de dissipação pode ocorrer se a probabilidade de ocorrência das pressões de vapor atingir $1 \%$ em termos de freqüência.

Como o objetivo deste trabalho é estabelecer um critério de projeto que permita a definição do risco de incipiência de cavitação, nos degraus localizados na região não aerada do escoamento, determinaram-se, a partir dos dados das aquisições de pressões instantâneas, as pressões negativas nos piezômetros $1,2,3$ e 5 , com probabilidade de ocorrência de $1 \%$ e $2 \%$. Essas pressões, para cada teste, são apresentadas no quadro 2 , bem como o parâmetro adimensional que relaciona a profundidade do escoamento $\mathrm{h}$ e a rugosidade $\mathrm{k} \mathrm{e}$, ainda, a velocidade do escoamento correspondente no protótipo, para a condição de um vertedouro com calha vertedoura construída de degraus com 0,60 m. Os resultados constantes do quadro 2 foram plotados nas figuras 23 e 24 .

$\mathrm{Na}$ figura 23, foram plotadas as velocidades médias contra a relação $\mathrm{h} / \mathrm{k}$, de cada teste, materializando pontos experimentais, junto aos quais, estão expressas as pressões que as identificam se: pressão de vapor $\left(p_{v}\right)$, inferiores ou superiores à -9 m.c.a., com probabilidade de ocorrência de 1\%. Na figura 24, de maneira análoga, representou-se a curva definida e os pontos experimentais representativos das pressões com probabilidade de $2 \%$.

Analisando-se os resultados experimentais, plotados na figura 23, estabeleceu-se uma curva através dos pontos experimentais. A região do gráfico acima dessa curva identifica as relações entre a velocidade média do escoamento e a relação $\mathrm{h} / \mathrm{k}$ para qual prevê-se o risco de incipiência da cavitação

A declividade da linha divisória foi estabelecida com base nos resultados de Tozzi (1992) ilustrados na figura 25. Para a curva correspondente à freqüência de $1 \%$ naquela figura, admitiu-se pressão negativa igual às condições de cavitação $(p / \gamma=-9,5$ m.c.a.), calculando-se os pares de valores $(\mathrm{V}, \mathrm{h} / \mathrm{k})$ correspondentes, e definindo a curva tracejada das figuras 23 e 24. Observa-se que face à precisão dos resultados experimentais, a diferença de probabilidade entre $1 \%$ e $2 \%$ pouco altera o critério.

A definição do gráfico na figura 23 considerou os pontos experimentais de pressões instantâneas subatmosféricas que atingem pressões menores que -9,5 m.c.a., com probabilidade de ocorrência de 1\%. A adoção desse critério é subjetivo, considerando-se serem os resultados qualitativos e restritos. Contudo, cabe aqui destacar, que Lopardo et al. (1982) em suas investigações sobre a tendência à cavitação, devida à macro turbulência do ressalto hidráulico, conduzida no modelo reduzido e no protótipo da barragem de Salto Grande, concluíram, a partir de uma análise estatística das pressões medidas no modeloprotótipo, que com a probabilidade de $1 \%$ de ocorrência de pressões, que atingem a pressão de vapor, ocorre a cavitação. 
Quadro 2 - Pressões que conduzem à incipiência de cavitação.

\begin{tabular}{|c|c|c|c|c|c|c|c|c|c|c|c|c|}
\hline \multirow{3}{*}{$\begin{array}{c}\text { SERIE } \\
\text { ESCALA }\end{array}$} & \multirow{3}{*}{ ENSAIO } & \multirow{3}{*}{ TESTE } & \multirow{3}{*}{$\begin{array}{c}\text { PARÁMETRO } \\
\mathrm{h} / \mathrm{k} \\
\text { (adimensional) }\end{array}$} & \multirow{3}{*}{$\begin{array}{c}\text { VELOCIDADE } \\
\text { U } \\
(\mathrm{m} / \mathrm{s})\end{array}$} & \multicolumn{8}{|c|}{$\begin{array}{l}\text { PRESSÖES INSTANTĀNEAS } \\
\text { (m.c.a.) }\end{array}$} \\
\hline & & & & & \multicolumn{4}{|c|}{ PROBABILIDADE DE $1 \%$} & \multicolumn{4}{|c|}{ PROBABILIDADE DE $2 \%$} \\
\hline & & & & & $\overline{\text { PIEZ. } 1}$ & $\overline{\text { PIEZ. } 2}$ & PIEZ. 3 & PIEZ. 5 & $\overline{\text { PIEZ. } 1}$ & PIEZ. 2 & PIEZ. 3 & PIEZ. 5 \\
\hline \multirow{6}{*}{$\begin{array}{c}01 \\
1: 5\end{array}$} & & 01 & 2,7 & 22,44 & $-4,743$ & $-2,449$ & $-3,749$ & $-2,587$ & $-4,719$ & $-2,199$ & $-3,220$ & $-2,193$ \\
\hline & 01 & 02 & 2,6 & 19,49 & $-4,121$ & $-1,879$ & $-3,188$ & $-2,042$ & $-3,577$ & $-1,613$ & $-2,696$ & $-1,755$ \\
\hline & & 03 & 2,3 & 15,96 & $-3,124$ & $-1,459$ & $-2,385$ & $-1,517$ & $-2,655$ & $-1,250$ & $-2,077$ & $-1,343$ \\
\hline & & 01 & 2,2 & 22,70 & $-5,360$ & $-2,641$ & $-3,771$ & $-2,554$ & $-4,789$ & $-2,399$ & $-3,272$ & $-2,254$ \\
\hline & 02 & 02 & 2,0 & 18,61 & $-3,748$ & $-1,760$ & $-2,898$ & $-1,978$ & $-3,392$ & $-1,591$ & $-2,603$ & $-1,781$ \\
\hline & & 03 & 1,8 & 15,22 & $-3,080$ & $-1,547$ & $-2,693$ & $-1,581$ & $-2,649$ & $-1,376$ & $-2,319$ & $-1,381$ \\
\hline \multirow{9}{*}{$\begin{array}{c}02 \\
1: 10\end{array}$} & & 04 & 2,9 & 24,30 & $-7,954$ & $-6,146$ & $\mathrm{PV}$ & $\mathrm{PV}$ & $-6,894$ & $-5,367$ & $\mathrm{PV}$ & $-9,034$ \\
\hline & 03 & 05 & 2,8 & 22,30 & $-7,163$ & $-5,650$ & $\mathrm{PV}$ & $-9,034$ & $-6,268$ & $-4,886$ & $-9,474$ & $-7,480$ \\
\hline & & 06 & 2,6 & 18,81 & $-5,868$ & $-4,507$ & $-8,503$ & $-6,373$ & $-5,000$ & $-3,919$ & $-7,048$ & $-5,293$ \\
\hline & & 07 & 2,3 & 16,51 & $-4,313$ & $-3,457$ & $-6,057$ & $-4,132$ & $-3,717$ & $-3,017$ & $-5,170$ & $-3,393$ \\
\hline & & 04 & 2,3 & 30,45 & $\mathrm{PV}$ & $-8,519$ & $\mathrm{PV}$ & $\mathrm{PV}$ & $-9,483$ & $-7,431$ & $\mathrm{PV}$ & $\mathrm{PV}$ \\
\hline & & 05 & 2,4 & 24,63 & $-9,452$ & $-7,909$ & $\mathrm{Pv}$ & $\mathrm{Pv}$ & $-8,104$ & $-6,806$ & $-9,393$ & $-9,489$ \\
\hline & 04 & 06 & 2,2 & 22,06 & $-7,725$ & $-3,848$ & $-9,064$ & $-8,445$ & $-6,663$ & $-3,388$ & $-7,809$ & $-7,249$ \\
\hline & & 07 & 2,1 & 18,05 & $-5,585$ & $-2,971$ & $-6,605$ & $-5,259$ & $-4,811$ & $-2,584$ & $-5,499$ & $-4,389$ \\
\hline & & 08 & 1,9 & 15,17 & $-4,538$ & $-2,094$ & $-5,371$ & $-3,748$ & $-3,736$ & $-1,810$ & $-4,543$ & $-3,147$ \\
\hline \multirow{12}{*}{$\begin{array}{c}03 \\
1: 20\end{array}$} & & 01 & 3,1 & 43,44 & \# & $-8,994$ & $\overline{P V}$ & $\mathrm{PV}$ & \# & $-7,789$ & $\overline{P V}$ & $\mathrm{PV}$ \\
\hline & & 02 & 3,0 & 36,34 & \# & $-8,626$ & Pv & Pv & \# & $-5,566$ & $\mathrm{PV}$ & $\mathrm{PV}$ \\
\hline & 01 & 03 & 2,9 & 28,87 & \# & $-5,319$ & $\mathrm{Pv}$ & $\mathrm{PV}$ & \# & $-4,475$ & $-8,644$ & $-8,695$ \\
\hline & & 04 & 2,5 & 24,56 & \# & $-3,765$ & $-6,938$ & $-7,454$ & \# & $-3,065$ & $-5,924$ & $-6,172$ \\
\hline & & 05 & 2,4 & 21,38 & \# & $-3,219$ & $-6,431$ & $-5,970$ & \# & $-2,663$ & $-5,417$ & $-5,143$ \\
\hline & & 06 & 2,1 & 18,52 & \# & $-2,560$ & $-6,131$ & $-6,082$ & \# & $-1,964$ & $-5,117$ & $-5,244$ \\
\hline & & 01 & 2,2 & 44,02 & \# & $-9,270$ & $\mathrm{PV}$ & $\mathrm{PV}$ & $\#$ & $-8,169$ & $\mathrm{PV}$ & PV \\
\hline & & 02 & 2,2 & 39,30 & \# & $-8,169$ & $\mathrm{Pv}$ & $\mathrm{PV}$ & \# & $-7,119$ & PV & Pv \\
\hline & 02 & 03 & 2,1 & 30,58 & \# & $-6,553$ & $\mathrm{PV}$ & $\mathrm{PV}$ & \# & $-6,007$ & PV & $P V$ \\
\hline & & 04 & 1,9 & 27,45 & \# & $-5,204$ & $-9,115$ & $-9,180$ & \# & $-4,803$ & $-8,014$ & $-7,980$ \\
\hline & & 05 & 1,7 & 22,84 & \# & $-4,248$ & $-8,158$ & $-8,478$ & \# & $-4,145$ & $-7,172$ & $-7,339$ \\
\hline & & 06 & 1,5 & 18,30 & \# & $-3,496$ & $-7,196$ & $-6,892$ & $\#$ & $-3,095$ & $-5,656$ & $-5,905$ \\
\hline
\end{tabular}

Notas:

a) U: velocidade média obtida a partir das profundidades do modelo;

b) h: profundidade do escoamento obtida nos testes:

c) k: rugosidade da calha;

d) Pv: pressão de vapor, correspondente à pressões negativas menores que - 9,5 m.c.a..

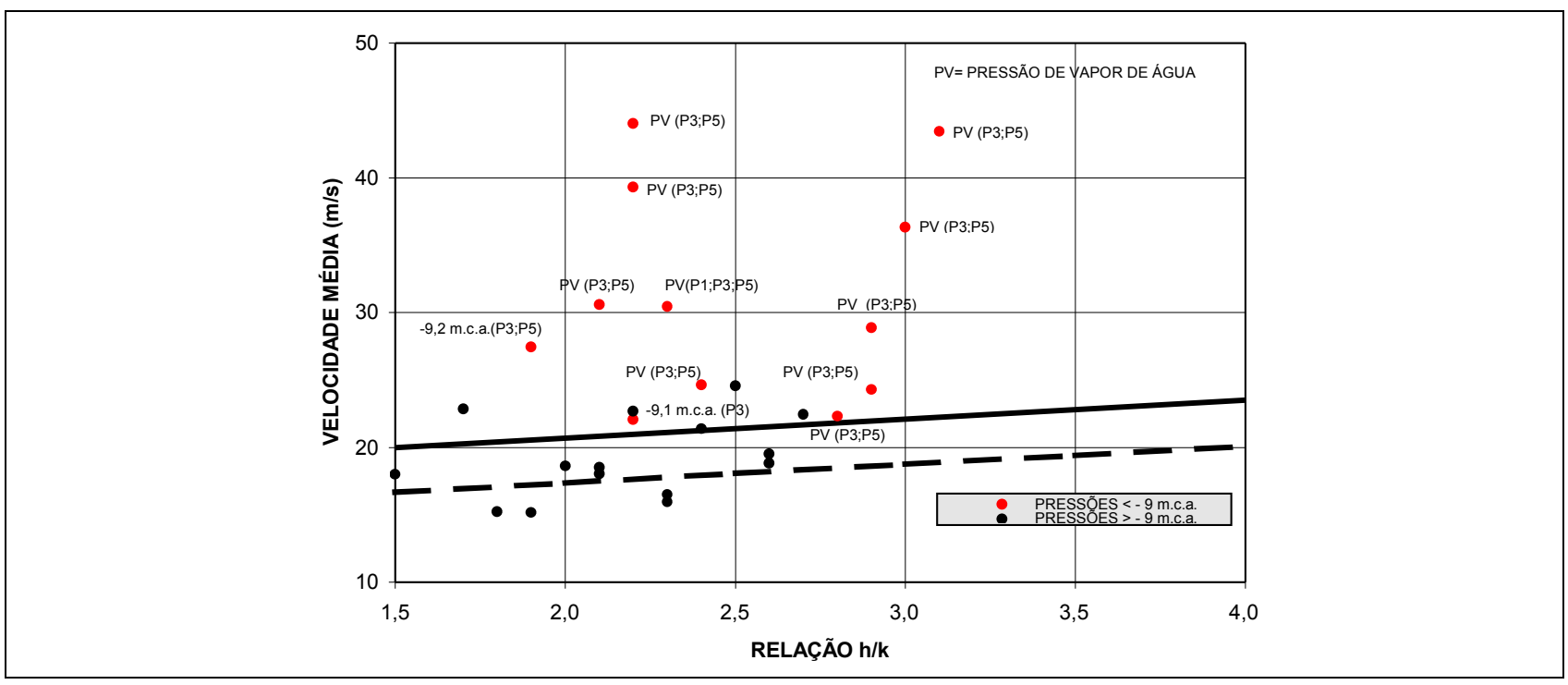

Figura 23 - Gráfico ilustrativo do risco de cavitação incipiente nos degraus do vertedouro - Freqüência de $1 \%$. 


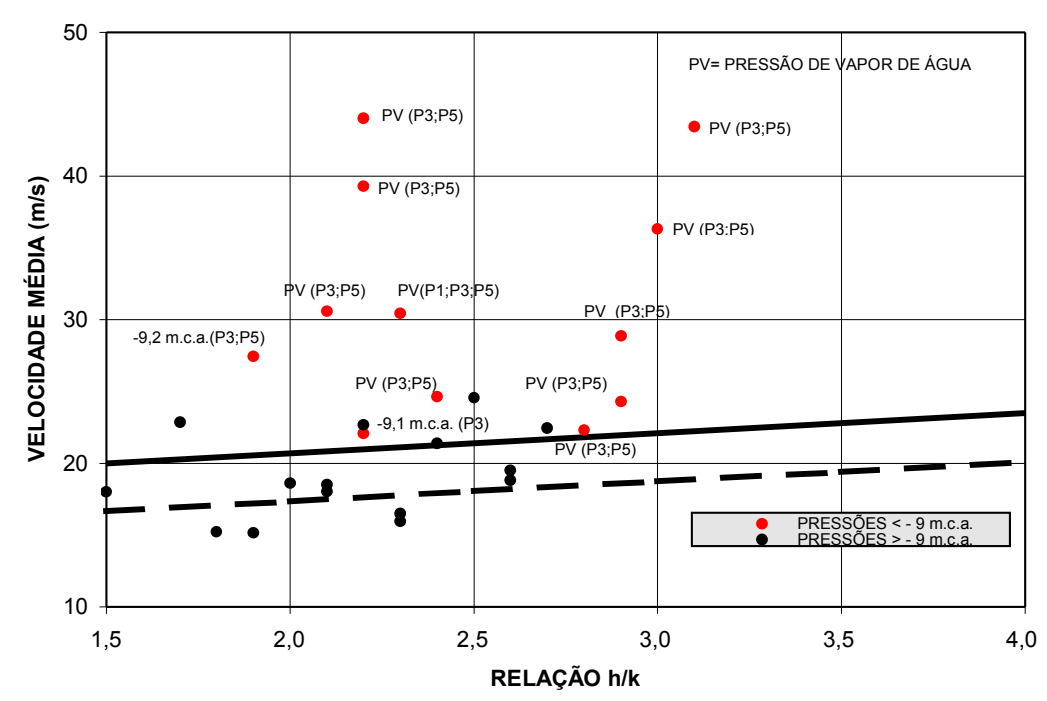

Figura 24 - Gráfico ilustrativo do risco de cavitação incipiente nos degraus do vertedouro - Freqüência de $2 \%$.

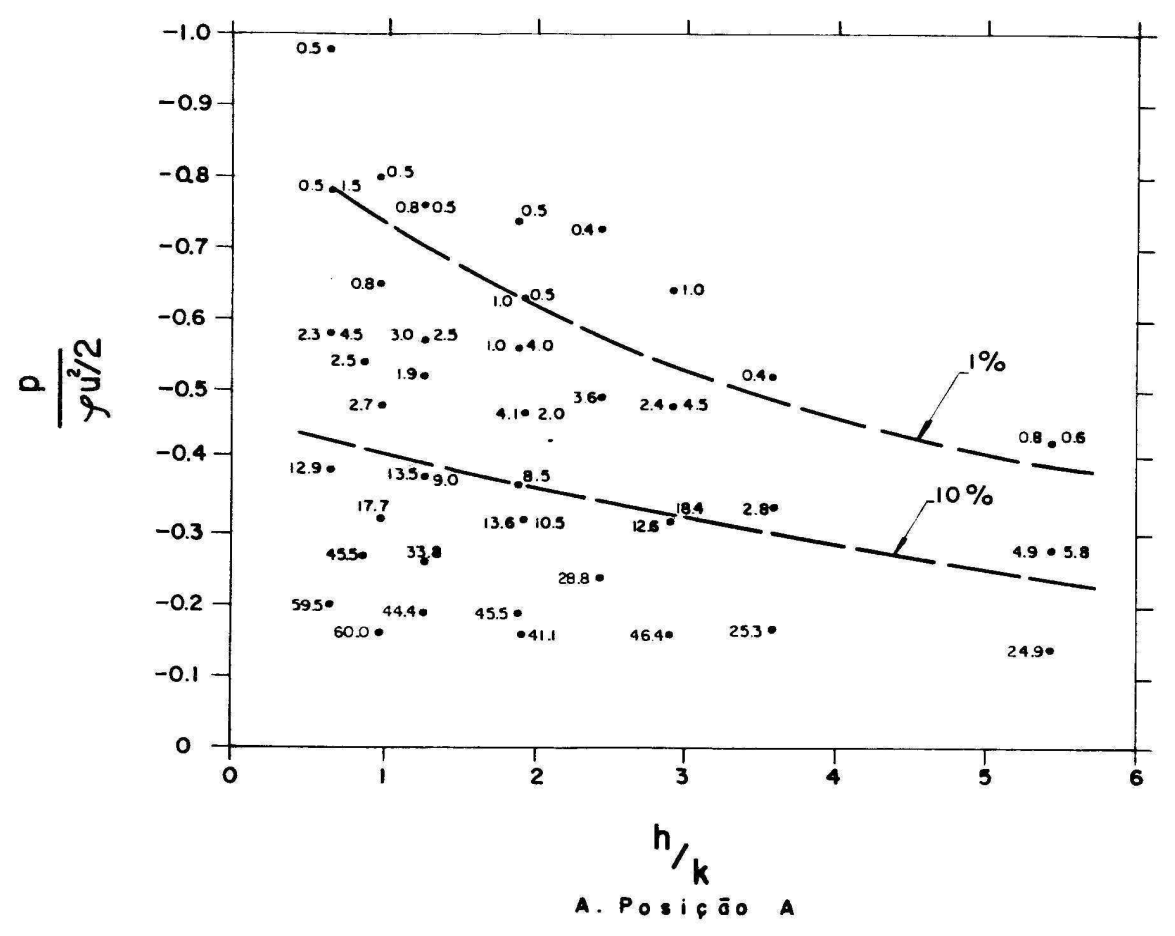

Figura 25 - Relação entre os adimensionais $\left(\frac{p}{\rho U^{2} / 2}\right) \times\left(\frac{h}{k}\right)$ e as correspondentes porcentagens de ocorrência das pressões - Tozzi (1992). 
Sabendo-se, que o risco de ocorrer a cavitação nos degraus, é maior no trecho da calha onde o escoamento não é totalmente aerado, efetuou-se uma verificação calculando-se o início da aeração na calha de um vertedouro, cuja configuração é ilustrada, em dimensões de protótipo, na figura 26. A configuração da ogiva e do trecho de calha, apresentada na figura 26, é semelhante a do Aproveitamento Hidrelétrico de Dona Francisca localizada no rio Jacuí ( Rio Grande do sul - Brasil). O vertedouro dessa obra, em função de sua altura, não corre o risco de cavitação. Para efeito dos cálculos, no presente trabalho, a calha com degraus foi aumentada em seu comprimento para definição da posição de início da aeração. O cálculo do inicio da aeração foi realizado para as mesmas vazões unitárias impostas nos testes realizados no modelo físico experimental (ver quadro 1), transportadas para o protótipo, considerando-se os degraus com $0,60 \mathrm{~m}$.

O cálculo teórico das posições do início de aeração do escoamento foram obtidas utilizando-se a metodologia proposta por Tozzi (1992) aplicada à calha do vertedouro com inclinação 1,0V:0,75H (inclinação da calha igual a $53,13^{\circ}$ ) e rugosidade $\mathrm{k}=0,36 \mathrm{~m}$, ilustrada na figura 26.

Os cálculos foram realizados considerando a ocorrência da altura crítica na crista do vertedouro (el.
$94,50 \mathrm{~m}$ ), altura de rugosidade $\mathrm{k}$ do trecho liso da calha igual a $0,0006 \mathrm{~m}$ e coeficiente de Coriolis igual a 1,10. As posições de início da aeração correspondem ao local onde a profundidade h do fluxo é igual a espessura da camada limite . A avaliação da profundidade h foi obtida pelo cálculo do perfil do escoamento utilizando-se o Standard Step Method (método das diferenças finitas) apresentado por Chow (1959) e a espessura da camada limite foi determinada pelas equações propostas pelo - ESTADOS UNIDOS. Corps of Engineers (1977).

O quadro 3 resume os resultados obtidos, apresentando: a carga hidráulica $\mathrm{H} 1$ sobre a crista do vertedouro; a profundidade $h$ na posição do início da aeração; o degrau a partir do qual inicia a aeração; a cota do degrau; o comprimento La, correspondente ao comprimento do desenvolvimento da camada limite até a posição onde a espessura da camada limite é igual a profundidade (h) do fluxo; a altura $\mathrm{H} 2$, distância vertical entre o degrau em que inicia a aeração e a crista do vertedouro; a altura $\mathrm{H} 3$, carga hidráulica sobre o degrau onde inicia a aeração $(\mathrm{H} 1+\mathrm{H} 2)$ e a velocidade do escoamento na posição onde inicia a aeração.

Comparando-se os resultados de profundidade $\mathrm{h}$ do escoamento, na posição do inicio da aeração, apresenta-

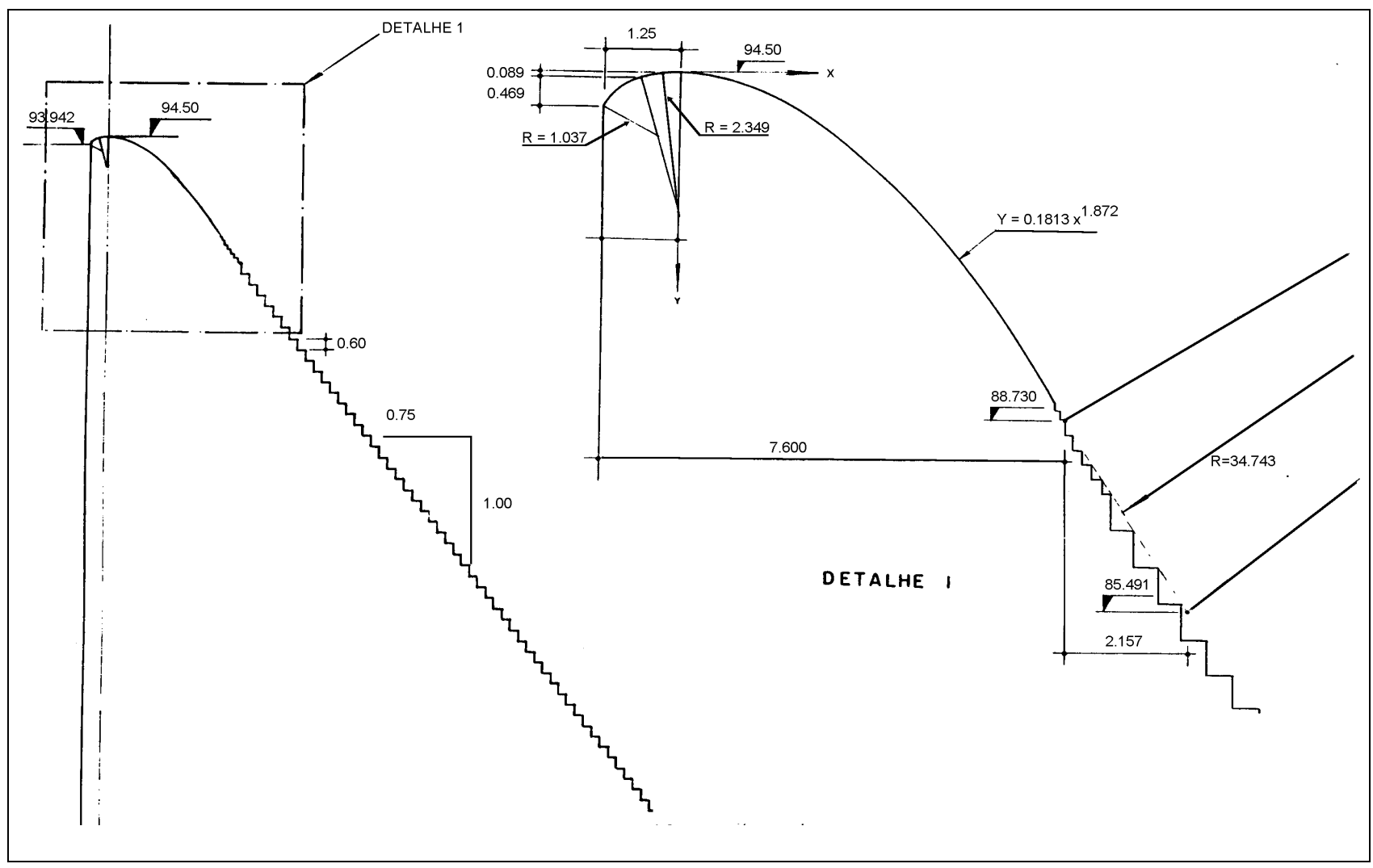

Figura 26 - Configuração da soleira vertedoura usada nos cálculos do presente estudo. 
Quadro 3 - Posição do início da aeração na calha vertedoura em degraus.

Cota da crista do vertedouro: 94,50 m - degrau de 0,60 m - inclinação do paramento em degraus 1V:0,75H

\begin{tabular}{|c|c|c|c|c|c|c|c|c|c|c|c|}
\hline $\begin{array}{l}\text { SÉRIE } \\
\text { ESCALA }\end{array}$ & ENSAIO & TESTE & \begin{tabular}{|c|} 
VAZÃO \\
UNITÁRIA \\
$\mathbf{q}$ \\
$\left(\mathrm{m}^{3} / \mathrm{s} . \mathrm{m}\right)$
\end{tabular} & \begin{tabular}{|c} 
CARGA \\
HIDRÁUL \\
H1 \\
$(\mathrm{m})$
\end{tabular} & $\begin{array}{c}\text { PROF. } \\
\text { h } \\
(\mathrm{m})\end{array}$ & $\begin{array}{c}\text { DEGRAU } \\
\mathrm{n}^{\circ}\end{array}$ & $\begin{array}{c}\text { COTA DO } \\
\text { DEGRAU } \\
(\mathrm{m})\end{array}$ & $\begin{array}{l}\text { COMPRIM } \\
\text { La } \\
(\mathrm{m})\end{array}$ & $\begin{array}{c}\text { ALTURA } \\
\text { H2 } \\
(\mathrm{m})\end{array}$ & $\begin{array}{c}\text { ALTURA } \\
\text { H3 } \\
\text { (m) }\end{array}$ & $\begin{array}{c}\text { VELOC. } \\
\underset{(\mathrm{m} / \mathrm{s})}{\mathbf{U}}\end{array}$ \\
\hline 01 & 01 & $\begin{array}{l}01 \\
02 \\
03\end{array}$ & \begin{tabular}{|l|}
21,99 \\
17,94 \\
13,40 \\
\end{tabular} & \begin{tabular}{|l|}
4,95 \\
4,32 \\
3,55 \\
\end{tabular} & $\begin{array}{l}1,08 \\
0,96 \\
0,80\end{array}$ & $\begin{array}{l}44 \\
36 \\
26\end{array}$ & $\begin{array}{l}65,30 \\
70,10 \\
76,10\end{array}$ & $\begin{array}{l}40,78 \\
34,78 \\
27,28\end{array}$ & $\begin{array}{l}29,20 \\
24,40 \\
18,40 \\
\end{array}$ & $\begin{array}{l}34,15 \\
28,72 \\
21,95 \\
\end{array}$ & $\begin{array}{l}20,36 \\
18,68 \\
16,75\end{array}$ \\
\hline $1: 5$ & 02 & $\begin{array}{l}01 \\
02 \\
03\end{array}$ & $\begin{array}{l}17,94 \\
13,40 \\
10,05\end{array}$ & $\begin{array}{l}, 32 \\
3,55 \\
2,93\end{array}$ & $\begin{array}{l}0,96 \\
0,80 \\
0,67\end{array}$ & $\begin{array}{l}36 \\
26 \\
18\end{array}$ & $\begin{array}{l}70,10 \\
76,10 \\
80,90\end{array}$ & $\begin{array}{l}34,78 \\
27,28 \\
21,28\end{array}$ & $\begin{array}{l}24,40 \\
18,40 \\
13,60\end{array}$ & $\begin{array}{l}28,72 \\
21,95 \\
16,53\end{array}$ & $\begin{array}{l}18,68 \\
16,75 \\
15,00\end{array}$ \\
\hline 02 & 03 & $\begin{array}{l}04 \\
05 \\
06 \\
07\end{array}$ & $\begin{array}{l}25,27 \\
22,52 \\
17,87 \\
13,71\end{array}$ & $\begin{array}{l}5,43 \\
5,02 \\
4,31 \\
3,61\end{array}$ & $\begin{array}{l}1,17 \\
1,10 \\
0,91 \\
0,82\end{array}$ & $\begin{array}{l}50 \\
46 \\
36 \\
28 \\
\end{array}$ & $\begin{array}{l}61,70 \\
64,10 \\
70,10 \\
74,90\end{array}$ & $\begin{array}{l}45,28 \\
42,28 \\
34,78 \\
28,78 \\
\end{array}$ & $\begin{array}{l}32,80 \\
30,40 \\
24,40 \\
19,60\end{array}$ & $\begin{array}{l}38,23 \\
35,42 \\
28,71 \\
23,21\end{array}$ & $\begin{array}{l}21,60 \\
20,47 \\
18,81 \\
16,71\end{array}$ \\
\hline $1: 10$ & 04 & $\begin{array}{l}04 \\
05 \\
06 \\
07 \\
08\end{array}$ & $\begin{array}{l}25,27 \\
21,67 \\
17,87 \\
13,36 \\
10,17\end{array}$ & $\begin{array}{l}5,43 \\
4,90 \\
4,31 \\
3,55 \\
2,96\end{array}$ & $\begin{array}{l}1,17 \\
1,08 \\
0,96 \\
0,80 \\
0,67\end{array}$ & $\begin{array}{l}50 \\
44 \\
30 \\
26 \\
18\end{array}$ & $\begin{array}{l}61,70 \\
65,30 \\
70,10 \\
76,10 \\
80,90\end{array}$ & $\begin{array}{l}45,28 \\
40,78 \\
34,78 \\
27,28 \\
21,28\end{array}$ & $\begin{array}{l}32,80 \\
29,20 \\
24,40 \\
18,40 \\
13,60\end{array}$ & $\begin{array}{l}38,23 \\
34,10 \\
28,71 \\
21,95 \\
16,56\end{array}$ & $\begin{array}{l}21,60 \\
20,07 \\
18,62 \\
16,70 \\
15,17\end{array}$ \\
\hline 03 & 01 & $\begin{array}{l}01 \\
02 \\
03 \\
04 \\
05 \\
06 \\
\end{array}$ & $\begin{array}{l}48,65 \\
39,25 \\
30,03 \\
22,10 \\
18,39 \\
13,71\end{array}$ & $\begin{array}{l}8,40 \\
7,28 \\
6,09 \\
4,96 \\
4,39 \\
3,61\end{array}$ & $\begin{array}{l}1,74 \\
1,53 \\
1,30 \\
1,08 \\
0,98 \\
0,82\end{array}$ & $\begin{array}{l}90 \\
76 \\
60 \\
44 \\
36 \\
28 \\
\end{array}$ & $\begin{array}{l}37,70 \\
46,10 \\
55,70 \\
65,30 \\
70,10 \\
74,90\end{array}$ & $\begin{array}{l}75,28 \\
64,78 \\
52,78 \\
40,78 \\
34,78 \\
28,78\end{array}$ & $\begin{array}{l}56,80 \\
48,40 \\
38,80 \\
29,20 \\
24,40 \\
19,60\end{array}$ & $\begin{array}{l}65,20 \\
55,68 \\
44,89 \\
34,16 \\
28,79 \\
23,21\end{array}$ & $\begin{array}{l}27,96 \\
25,65 \\
23,10 \\
20,46 \\
18,76 \\
16,71\end{array}$ \\
\hline $1: 20$ & 02 & $\begin{array}{l}01 \\
02 \\
03 \\
04 \\
05 \\
06\end{array}$ & $\begin{array}{c}35,21 \\
3,65 \\
22,94 \\
18,39 \\
13,71 \\
9,88\end{array}$ & $\begin{array}{l}6,77 \\
6,17 \\
5,09 \\
4,39 \\
3,61 \\
2,90\end{array}$ & $\begin{array}{l}1,44 \\
1,32 \\
1,11 \\
0,98 \\
0,82 \\
0,67\end{array}$ & $\begin{array}{l}68 \\
60 \\
46 \\
36 \\
28 \\
18 \\
\end{array}$ & $\begin{array}{l}50,90 \\
55,70 \\
64,10 \\
70,10 \\
74,90 \\
80,90\end{array}$ & $\begin{array}{l}58,78 \\
52,78 \\
42,28 \\
34,78 \\
28,78 \\
21,28\end{array}$ & $\begin{array}{l}43,60 \\
38,80 \\
30,40 \\
24,40 \\
19,60 \\
13,60\end{array}$ & $\begin{array}{l}50,37 \\
44,97 \\
35,49 \\
28.79 \\
23,21 \\
16,50\end{array}$ & $\begin{array}{l}24,45 \\
23,22 \\
20,66 \\
18,76 \\
16,71 \\
14,75\end{array}$ \\
\hline
\end{tabular}

Notas:
a) q: vazão unitária no protótipo;
b) H1: carga hidraulica - corresponde a diferença entre o nível de água no reservatório e a cota da crista do vertedouro;
c) h: profundidade do escoamento na posição do início de aeração sobre a calha;
d) $\quad \mathrm{N}^{\circ}$ do degrau: corresponde ao número do degrau contado a partir do final do trecho liso da soleira vertedoura;
e) La: corresponde ao comprimento do desenvolvimento da camada limite até a posição do início da aeração;
f) H2: correspondente a altura entre a cota da crista do vertedouro e a cota do degrau;
g) H3: corresponde a altura entre o nível de água no reservatório e a cota do degrau;
h) U: velocidade média na seção da posição do início de aeração.

dos no quadro 3, com as respectivas profundidades obtidas nos testes (através da velocidade média obtida por integração dos perfis de velocidades), constata-se, que na maioria dos testes, as profundidades determinadas pela proposição de Tozzi (1992) são maiores. Isto significaria, a princípio, que as pressões obtidas no presente estudo teriam sido medidas na zona aerada do escoamento, e portanto, o risco de incipiência de cavitação nos degraus, nessa região, seria menor. Sabe-se, entretanto, que a definição correta da posição dos degraus onde a aeração está presente é suficiente para inibir a cavitação, ainda não é bem conhecida. Povh (2000), observando o comportamento do escoamento, comenta que a definição do posicionamento do inicio de aeração da calha é bastante complexa. Em seu estudo, conduzido no modelo reduzido de Dona Francisca, definiu 4 posições de aeração ao longo da calha:

- aeração da superfície livre da água: identificada na posição onde o perfil da linha de água começou a ter oscilações provocada pela incorporação de ar no escoamento;

- aeração intermitente dos degraus: caracterizada pela presença intermitente de ar nos vórtices que ocorrem na cavidade entre degraus adjacentes;

- aeração contínua dos degraus: identificada como a posição em que o fluxo na superfície da água é conti- 
nuamente aerado e no interior da cavidade dos degraus o vórtice é continuamente aerado, porém de forma intermitente;

- aeração total do fluxo ao longo da profundidade: caracterizada como sendo a posição onde a aeração do fluxo proveniente da superfície livre da água e dos degraus se encontram de uma forma praticamente permanente, abrangendo toda a profundidade.

Utilizando a metodologia proposta por Tozzi (1992), Povh (2000) determinou, para os diferentes valores da vazão específica, a posição do inicio de aeração do escoamento, concluindo que os resultados foram próximos ao obtidos para o inicio da aeração intermitente.

Observando-se os resultados do quadro 3, notase, por exemplo, que no teste 05 da série 02 - ensaio 03 e no teste 05 da série 02 - ensaio 04 as profundidades obtidas por via analítica e experimental são praticamente as mesmas, e que, nesses testes, registraram-se pressões subatmosféricas no piezômetro 3, indicando risco de cavitação no degrau. O critério de projeto para incipiência da cavitação nos degraus, definido na figura 23, estará a favor da segurança, se for levado em conta que as pressões subatmosféricas foram medidas em um degrau com maior taxa de aeração, localizado a jusante da posição do inicio da aeração, definido analiticamente. Cabe aqui enfatizar, mais uma vez, que os testes no canal experimental foram realizados com o degrau instrumentado posicionado no trecho não aerado do escoamento.

\section{CONCLUSÕES}

$\mathrm{Na}$ engenharia de obras hidráulicas de grande porte o risco de cavitação nos degraus de vertedouros é um assunto de interesse investigativo. Os resultados apresentados neste estudo são uma contribuição ao entendimento do comportamento das distribuições de pressão nos degraus e à avaliação das condições de cavitação incipiente. $\mathrm{O}$ aspecto geral das distribuições de pressão nos degraus foi definido para duas relações $\mathrm{h} / \mathrm{k}$ (profundidade/ altura do degrau) e para a gama de número de Froude de 5,5 a 17,0, com base em dados de modelos nas escalas 1:5, 1:10 e 1:20 de um degrau de $0,60 \mathrm{~m}$ no protótipo.

As principais conclusões desta investigação experimental sobre um paramento com declividade $1 \mathrm{~V}: 0,75 \mathrm{H}$, típica de barragens a gravidade, são apresentadas na seqüência.

- os perfis de velocidade do escoamento, obtidos nos ensaios mostraram uma distribuição das velocidades bem definida. Na região da camada limite turbulenta, os pontos experimentais ajustaram-se bem à distribuição logarítmica de velocidades definida por Tozzi (1992);
- as pressões médias negativas no espelho do degrau praticamente independem do número de Froude do escoamento;

- as pressões médias positivas na extremidade da base do degrau mostram uma relação bem definida das pressões com o número de Froude para cada relação de $\mathrm{h} / \mathrm{k}$;

- quanto maior a velocidade média do escoamento maiores são as pressões negativas, para cada freqüência de ocorrência considerada;

- as bases para o estabelecimento de um critério de projeto que permita avaliar a possibilidade de ocorrência de cavitação nos degraus, ficam estabelecidas a partir da representação gráfica apresentada. Com o conhecimento da velocidade média do escoamento $(\mathrm{U})$, da profundidade do escoamento (h) na posição do degrau a ser avaliado e da rugosidade $(\mathrm{k})$, é possível definir o risco de cavitação em função das pressões negativas que atingem a pressão de vapor, na prática, $p / \gamma$ menores que - 9,5 m.c.a., com freqüência de $1 \%$ ou $2 \%$

\section{REFERÊNCIAS}

CHOW, Ven Te. Open channel hydraulics. New York: McGrawHill, 1959.

ELVIRO, V.; MATEOS, C. Spanish research into stepped spillways. The International Journal on Hydropower \& Dams, v. 2, n. 5, p. 61-65, 1995.

ESTADOS UNIDOS. Corps of Engineers. Hydraulic design criteria. Vicksburg, 1977. sheets $111-18$ to $111-18 / 5$

FRIZELL, K. H. Stepped spillway design for flow over embankments. In: NATIONAL CONFERENCE OF HYDRAULIC ENGINEERING, 1991, Nashville. Proceedings. New York: ASCE 1991. p. 118-123.

HOUSTON, K. L.; RICHARDSON, A.T. Energy dissipation characteristics of a stepped spillways. In: INTERNATIONAL SYMPOSIUM ON HYDRAULICS FOR HIGH DAMS, 1988. Beijing. Proceedings. Beijing: IAHR, 1988. p. 91-97.

LEJEUNE, M.; LEJEUNE, A. About the energy dissipation of skimming flows over stepped spillways. In: INTERNATIONAL CONFERENCE ON HYDROINFORMATICS, 1., 1994. Delft, Netherlands. Hidroinformatics'94: proceedings. Rotterdam: A. A. Balkema,1994. v. 2, p. 595-600.

LOPARDO, R. A.; DE LIO, J. C.; VERnET, G. F. Physical modeling cavitation tendency for macroturbulence of hydraulic jump. In: INTERNATIONAL CONFERENCE ON THE HYDRAULIC MODELLING OF CIVIL ENGINEEERING STRUTURES, Sept. 1982, Coventry, England. Papers ... Cranfield: BHRA Fluid Engineering, 1982. Paper C3, p.109 -121. 
MATOS, J. S. G. et al. Characteristic depth and pressure profiles in skimming flow over stepped spillway. In: CONGRESS IAHR, 28., Aug. 22-27,1999, Graz, Austria. Proceedings: abstract volume, papers on Cd - Rom. Graz, IAHR, 1999. p.158.

MEJIA FERNÁNDES, F. Investigacion en modelo hidraulico de un rebosadero escalonado. In: CONGRESSO LATINOAMERICANO DE HIDRAULICA, 16., 1994. Santiago, Chile. Memórias. Santiago: IAHR, 1994. v. 5 , p. 311-324.

POVH, P. H.; TOZZI, M.J. Fator de resistência em vertedouros com degraus. In: CONGRESSO LATINOAMERICANO DE HIDRÁULICA, 19., 2000, Córdoba. Memórias. Córdoba: IAHR, 2000, v. 2, p. 509-518.

POVH, P. H. Avaliação da energia residual a jusante de vertedouros em degraus com fluxos em regime skimming. Curitiba, 2000. 170 páginas. Dissertação ( Mestrado em Engenharia Hidráulica) Universidade Federal do Paraná.

RUBINSHTEIN, G. 1.; STEFANOVICH, G. H. Overflow earth dam with a stepped downstream face. Hydrotechnical Construction, v. 32, n. 10, p. 592-598, 1998.

SÁNCHES, M. J. Caracterización del campo de pressiones sobre um aliviadero escalonado:

In: CONGRESO LATINOAMERICANO DE HIDRAULICA, 18., 1998, México. Memórias. México: IAHR, 1998. v. 2, p. 609-618.

TATE, C. H. Stepped spillway hydraulic model investigation, by Robert M. Sorensen. Journal of Hydraulic Engineering, ASCE, New York, v. 113, n. 8 , p.1096-1097, Aug. 1987. Discussão.

TOZZI, M. J. Caracterização / comportamento de escoamentos em vertedouros com paramento em degraus. São Paulo, 1992. 302 p. Tese (Doutorado) Universidade de São Paulo.

\section{Pressure Distribution in Stepped Spillways}

\section{ABSTRACT}

The advance of the use of Roller-Compacted Concrete (CCR-Concreto Compactado a Rolo) in dam-building has made it possible to build higher stepped spillways, subject to bydraulic heads and specific discharges greater than those that have been conventionally suggested for the project. Consequently, this evolution has caused designers to be concerned at the possibility of incipient cavitation on the steps located upstream from the aerated zone. Cavitation on the spillway steps is associated with the presence of negative pressures, especially in the upper vertical part of the step. The analytic/empirical determination of these pressures on the steps for so-called skimming flows constitutes a problem for which there is as yet no solution in the literature. The lack of design criteria that will take the risk of cavitation on the steps into account led to a systematic study based on experimental research to look at the influence of the main discharge variables on pressure distribution along the steps. The purpose of the present study was to use the results of investigation to establish nondimensional parameters that will enable relating the Froude number of the discharge to the pressures at any position on the steps. The main contribution of this study to looking at the possibility of incipient cavitation on the steps in the non-aerated region of the discharge is to find these relations. In order to evaluate this, based on these relations, it is enough to know specific discharge (q), mean discharge velocity (U), depth of discharge in the step position considered (b), flume slope (i) and roughness ( $k$ ) defined as the height of the normal step in relation to the flume level. This project received the contribution of Financiadora de Estudos e Projetos-FINEP (RECOPE/REHIDRO/SUB REDE 2) to purchase the data acquisition system and the pressure transducers.

Key-words: Stepped spillways; dam; pressure distribution. 